\title{
Giros en el pensamiento comunicacional. Para observar las observaciones en la configuración del campo académico de la comunicación en México.
}

Héctor Gómez Vargas

\section{La mirada en el centro. Para observar las observaciones del campo académico de la comunicación en México.}

Uno de los principales problemas en el proceso de generación de conocimiento se refiere a los procesos de objetivación. Es uno de los principales problemas porque el trabajo implica concentrarse en uno mismo como gestor del conocimiento, y en mantener una atención de máxima reflexividad'. Encarar esto, significa, entre otras cosas, reconocer la importancia del sujeto de conocimiento, pero, así mismo, reconocer que éste debe ser eminentemente un sujeto reflexivo, manejando permanentemente observaciones de distinto orden y nivel, donde en cada uno de esos niveles, se puede encontrar tas maneras y los procedimientos ocultos, ciegos y latentes, de cómo ha procedido y actuado (Ibáñez, 1998). Y es en ese punto donde el sujeto de conocimiento es parte de una serie de contextos, trayectorias y procesos que van desde lo individual, lo histórico, pasando por lo social y lo cultural (Gómez Vargas, 2003), delimitados dentro de sistemas de observaciones que un campo académico ha conformado como propio y necesario para su autonomía, desarrollo y reproducción. Una posibilidad de enfrentarlo, entonces, es a partir de la posición particular de uno como sujeto cognoscente, pues lo que lo conforma son las coordenadas que se cruzan incesantemente, un contexto personal, histórico y social' ${ }^{2}$.

I Al respecto, Pierre Bourdieu expresa que "el trabajo requerido por la objetivación científica se acompaña de un trabajo -en el sentido psicoanalítico del término- acerca del sujeto de la objetivación. No es posible trabajar sobre determinado objeto sin tener presente en todo momento que el sujeto de la objetivación está en sí mismo objetivado" (Bourdieu, 1995: 41).

${ }^{2}$ En este punto son sugerentes las propuestas de Hugo Zemelman, quien expresa: "El esfuerzo por abordar el problema de la realidad desde el compromiso del sujeto con sus valores y las posibilidades y limitaciones de su contexto, supone privilegiar los espacios de realidad según como éstos son acotados por los proyectos que asumen los individuos, o de los que son parte. $Y$ hacerlo significa 
A partir de estos planteamientos se pretende hacer una revision de algunos marcos desde los cuales quien escribe el presente trabajo ha participado, asimilado parte de lo que se ha configurado en el campo académico de la comunicación en México. Este ejercicio permite a quien lo realiza, encontrar las maneras como ha ido objetivando la manera de entender, conocer e investigar a la comunicación, que en mucho se puede apreciar de manera acabada en las investigaciones y artículos que ha escrito ${ }^{3}$. Pero, también, me parece que puede ser un ejercicio importante y necesario para el campo académico de la comunicación en su conjunto, pues en ello emerge ya sea una serie de circunstancias desde las cuales muchos han pretendido, y algunos lo han logrado, ingresar a generar conocimiento y reflexividad, y que de otra manera raras veces se torna visible, así como permite encontrar una serie de mecanismos que ayudan a entender algunas tendencias, procedimientos, obsesiones y reiteraciones, que en el momento presente pueden estar actuado como límites o posibilidades para pensar la comunicación.

Así mismo, el presente trabajo forma parte de los esfuerzos en el campo de la comunicación por desarrollar una serie de visitaciones a la manera como el mismo campo se ha institucionalizado, y los discursos científicos que se han desarrollado (Vasallo de López y Fuentes Navarro, 2001), así como de los esfuerzos epistemológicos, metodológicos y teóricos que en los tiempos recientes se debaten en búsqueda de un pensamiento comunicacional (Fuentes, 1999; Vassallo de Lopes, 1999), y que dentro de las reflexiones sobre lo que toca investigar en los tiempos presentes, poco se especifica y se

pensar en términos de la construcción de sentido para enfrentar los acontecimientos tal como son incubados en su contexto; esto es, pensarlos en lo que tengan de articulable con otros de manera de potenciar a lo históricamente dado" (Zemelman, 1992: 10).

"El ejercicio de reflexividad que se ha realizado es más amplio y profundo de lo que aquí se va a presentar. Simplemente es un botón de muestra, y para ello sólo se detiene en trabajar en dos, de muchos otros, factores que tanto han sido importantes en la trayectoria académica y personal, como del mismo campo académico de la comunicación, por lo menos desde mediados de los ochentas a la fecha: el caso de la ciudad de Guadalajara y de Colima. La elección de detenernos en lo acontecido en ambas ciudades se expresará más adetante. simplemente basta decir por el momento que entender lo que ha sucedido con ellas, es entender en mucho gran parte del campo académico de la comunicación y parte de lo que se está fraguando en el presente. 
subraya, aunque es fundamental para entrar a la comprensión de la comunicación y a los medios masivos de comunicación.

\section{Pasajes de y en el campo académico de la comunicación en México.}

El campo académico de la comunicación tiene una historia corta dentro de la vida del conocimiento de lo social y lo humano. En e] caso de México, es una historia que se remite a unas cuantas décadas, pero donde han pasado varias cosas importantes, principalmente en la conformación de una comunidad de actores de conocimiento. La presencia de algunos de estos actores de conocimiento es fundamental, más allá de una serie de elementos, factores diversos y de diferente magnitud y nivel. En determinado momento de la historia del campo académico de la comunicación en México, algunos de ellos comenzaron a preguntarse sobre el mismo campo, y las reflexiones que emanaron de ellas, y a partir de entonces, han contribuido a darle ciertos giros, travesías y procedimientos.

Antes que ellos aparecieran, ya se habían dado algunos pasos para la apertura de la carrera de comunicacion, se formaron algunos modelos educativos básicos, se dieron algunos pasos para lo que se ha llamado la institucionalización del campo académico de la comunicación, pero fue a través de ellos que comenzó algo nuevo: a conformar una mirada de la comunicación y de la generación del conocimiento al preguntarse y preguntarle al campo de la comunicación sobre la manera como se habfa desarrollado y el tipo de conocimiento que se había gestado. Sus preguntas conformaron una mirada que desde entonces ha sido parte de las maneras o gúas como las siguientes generaciones de actores de conocimiento han tendido a actuar, al tenerlas como panoramas, horizontes y perspectivas para pensar y actuar en el campo académico de la comunicación. Sus miradas fueron producto de una experiencia social y cultural, por tanto son productos históricos y culturales. Han sido dos las tendencias que han prevalecido desde entonces para comprender y orientar la acción en el campo académico de la comunicación, la manera cómo configuraron y han configurado miradas. Las tendencias han sido, y son, a partir de agendas de lo investigable, es decir, por un lado "está la dimensión de reconstruirlos para intentar comprender cómo fue que sucedieron. Y por otra parte está la dimensión conceptual, la cosmológica, la que les otorga un sentido, los significa, los hace entendibles" (Galindo, 2002). 
Si bien se ha dicho que parte de lo que distingue a una persona que estudia comunicación es más un ethos (Godoy, 1994) que se va conformando a partir de ingresar a un "campo educativo", donde "un conjunto de prácticas interrelacionadas entre sí de acuerdo a la función que cumplen en la difusión del trabajo de producción, reproducción y difusión del conocimiento, entendido ampliamente como un conjunto de saberes y habilidades" (Orozco, 1990: 27-28), esto irá conformando una dimensión subjetiva y cognoscitiva que tanto integra como separa a los actores del conocimiento de la comunicación. De hecho, gran parte de los esfuerzos por comprender al campo de la comunicación desde las preguntas e indagaciones que se le hacen tienen como fines objetivar esa dimensión subjetiva (Fuentes, 1998: 11). Acuñar el mismo término "campo académico de la comunicación" fue un producto de un proceso que se dio para buscar una manera de comenzar a reorientar las acciones y de dar un salto en la reorganización de la actividad indagadora a nivel colectivo .

Una parte de las miradas fue poner atención a la noción de paradigma de acuerdo a la manera como la expuso Thomas Khun dentro de un debate mayor con el mundo científico en la década de los sesenta (Khun, 1986). Baste ver dos de los primeros libros que intentaron sistematizar el estudio de la comunicación, no en México, sino realizado por un mexicano. El primero es el libro de Comunicación de Antonio Paoli (1977) quien lo abordó desde los enfoques disciplinares, paradigmáticos que en otros lados del mundo

4 La reflexión de la enseñanza de la comunicación como una práctica educativa la inicia Guillermo Orozco, y que después otros retomarán, $y$ al hacerlo enfatiza su dimensión como producto social que implica una selección y una historicidad, más que algo espontáneo o una emergencia natural. Ver Orozco, 1990: 26.

'Es decir, el campo académico de la comunicación configuró a unos agentes de conocimientos, y éstos, a su vez, han configurado en gran parte al campo académico de la comunicación. Hay un antes que puede verse como una orientación y tendencia ontológica de la comunicacion: se establece como un programa de estudio, se buscan las orientaciones básicas y preliminares que llegan a conformar los modelos primarios y arquetípicos del estudio y perfil del profesional de la comunicación, se trabaja en la búsqueda de un reconocimiento como disciplina. Y hay un después a partir de la mitad de la década de los ochenta cuando se comienza a pasar a una visión reflexiva y constructiva y que ha sido entender la acción de la disciplina de la comunicación como un área de conocimiento, buscar su autonomía intelectual, su reconocimiento académico, intelectual y social. El futuro se instalo en las miradas. 
habían predominado y eran vigentes en esos momentos, y que eran, a su vez, parte de la manera como uno de los ejes, predominante en ese momento, del "modelo topologico" de la investigación social enfocaban y debatían sobre la comunicación: las sociologías del cambio radical, en un extremo, y las de la regulación por el otro (Rosengren, 1993). El segundo es el libro de Florence Toussaint (1975), crítica de la información de masas, que tuvo una estructura e intención paralela, y que fueron algunos de los lineamientos de otros libros más que aparecieron tiempo después, como los libros del español Miquel de Moragas (1981) que tuvieron amplia difusión y aceptación en México ${ }^{6}$.

El concepto de paradigma permitió comenzar a trabajar una idea que ya se sentía anteriormente: la importancia del trabajo colectivo en la generación de conocimiento, principalmente porque un paradigma de conocimiento implica una comunidad científica y que esta tiene una "existencia independiente" (Kuhn, 1987: 318), que trabaja a distintos niveles, que si bien, con el tiempo se hace difícil reconocer esos niveles señalados por Kuhn (generalizaciones simbólicas, modelos y ejemplares científicos", sí les permitió distinguir "diferentes referencias a marcos teórico-metodológicos de las ciencias sociales y/o las humanidades...a modelos heurísticos y hasta metafísicos más o menos compartidos, y a ciertos trabajos...parcialmente reconocidos como ejemplares" (Fuentes Navarro, 1998a: 246). Sin embargo, y referido al contexto de México y América Latina, la reflexión de la comunicación cobro una conciencia importante: el mismo lugar desde donde se intentaba pensarla y marcaba algunos de los hitos, condiciones y expectativas. Raúl Fuentes Navarro lo expresaba así:

El no haber tenido nunca la posibilidad, en América Latina, de convertirse en una "ciencia normal" a la Khun, es decir, de haber basado su desarrollo en torno a uno o varios "paradigmas", es lo que ahora proporciona la "movilidad" necesaria para seguir persiguiendo su objeto y generando socialmente sentido sobre la producción social de sentido... En síntesis, reconociendo que la producción de conocimiento sobre la comunicación es en sí misma una práctica sociocultural y comunicacional determinada histórica y

"De hecho, ese rnismo modelo es el que se siguió durante mucho tiempo no sólo en la ensef́anza de la investigación, sino también de las teorias de la comunicación en la mayoría de las universidades donde se impartía la carrera de comunicación en México (Gómez Vargas, 1990). 
estructuralmente, la discusión térica debería integrar a los investigadores comprometidos con el objeto de comunicación, independientemente de sus adscripciones disciplinarias, así como las metodologías de la investigación de la comunicación integran conceptos e instrumentos desarrollados en otros sectores de la ciencia social. De esta manera, creemos que el campo de la comunicación, desde la teoría, debe construirse al mismo tiempo como un enfoque con identidad específica y abierta a los intercambios con otros enfoques sobre la sociedad y la cultura (Fuentes Navarro, 1994: 64).

Las ideas expresadas por Raúl Fuentes sintetizan una serie de lecciones del pasado y parte de lo que sucedía en el momento de la enunciación. Por un lado, la integración y diálogo que se comenzó a dar con otros teóricos e investigadores de la comunicación, que ante un contex to similar de la aparición y desarrollo de los estudios de la comunicación, y con la ambición y visión de pertenecer a un mismo contexto y proceso historico, político, económico, social y cultural que agrupa e identifica (Márquez de Melo, 1993). En este proceso se dieron algunos factores que apoyaron la institucionalización del campo de la comunicación, a la reflexividad de lo que ha significado política e ideologicamente trabajar con "anteojeras" cientificas y teóricas que eran asumidas de manera natural, y por tanto a comenzar a pensar desde el "aquí y ahora", el reconocimiento de ser una disciplina en búsqueda de su objeto y del reconocimiento del campo académico de lo social. Pero por otro lado, esto mismo se impulsó ante lo que comenzaba a suceder: el mundo iniciaba a borrar y desintegrar una serie de procesos, estructuras, logicas y dinámicas de la manera como había sido, y, por tanto, pensado, y este pensamiento a su vez, comenzaba a ser evidente de su disolución de fronteras disciplinarias, y por lo mismo era necesario realizar tanto estados de la cuestión, como agendas pendientes y mapas que permitieran orientar la acción.

Es ahí cuando se comenzó a hablar del campo académico de la comunicación a principios de la década de los noventa, como un elemento que permitía objetivar la objetivación que hacían los agentes de conocimiento de la comunicacion, y tener marcos generales y compartidos para la búsqueda de la autonomía y legitimación 7 . La

'Fue Raúl Fuentes quien primero lo sef̂aló: "El concepto de campo (cultural, intelectual, académico, educativo), que debemos a Pierre Bourdieu y a quienes lo hayan difundido, explicado y desarrollado entre nosotros, nos permite reconocer las tensiones y los desfases entre los actores que lo constituyen con sus prícticas, más que los ingredientes y articulaciones relativamente estables y homogéneos 
definición del campo académico de la comunicación intentó generar mayor claridad de lo que se entiende por comunicación desde las prácticas académicas, educativas y profesionales de la misma. En sus inicios, el centro desde donde emanó todo fue la carrera de la comunicación y ésta tuvo desde un momento inicial un objeto, los medios de comunicacion, y un objetivo, formar a profesionistas que se encargaran de ellos, ya que, entre otras cosas, comenzó en una etapa donde los medios electrónicos de comunicación se expandieron $y$ crecieron. Ese fue el centro, $y$, al parecer lo sigue siendo8 .

También, a mediados de los ochentas sucedieron dos cosas importantes: por un lado, Raúl Fuentes inici 6 un trabajo de sistematización de lo que se había investigado de la comunicación a partir del archivo documental del CONEICC como una forma de generar conocimiento del campo desde lo que había sido la misma práctica sociocultural de investigación; por el otro lado, comenzó una

- las autorregulaciones con que un sistema preserva su identidad, esto es, su estructura. $Y$ es que to que intentamos enfatizar es el análisis del desarrollo sociocultural; no tanto el del crecimiento cuantitativo, ni tampoco el de la evolución estrictamente epistemologica. Por "campo académico" entendemos, entonces, a bastante más -de hecho otra cosa- que el conjunto de instituciones en que se estudia la comunicación a nivel superior. Incluimos en él a la teoría, la investigación, la formación universitaria y la profesión, y centramos el concepto en las prácticas que realizan actores o agentes sociales concretos -sujetos individuales y colectivos como nosotros- con el fin de impulsar proyectos sociales espećfficos: en este caso estructuras de conocimiento y pautas de intervencion sobre la comunicación social en nuestro país... De ahí que cuando se especifica "campo académico", no es a las prácticas sociales de comunicación (masivas o no) a las que se hace referencia, ni a las instituciones que se han especializado en su ejercicio y en su control social, sino a aquellas que toman a éstas como su referente, es decir, las que son realizadas principalmente por académicos (universitarios), con el proposito general de conocer, explicar e intervenir en la transformación intencionada de las prácticas sociales de comunicacion" (Fuentes Navarro, 1994: 70-7I).

"También a principios de los noventa se realizo un encuentro sobre el campo de la comunicación en México, y uno de los sentimientos generales era que se le identificaba con lo que sucede en las escuelas de comunicación, y éstas tenían como principal núcleo los medios de comunicación (Galindo, 1994: 26). En una revisión realizada por Claudia Benassinj hacfa ver que a finales de los noventa la tendencia prevalecía en las universidades donde se impartía la carrera de comunicacion, de acuerdo a la manera como se dieron los "modelos fundacionales" (Benassini, 1994, 1996), y no s6́lo eso, son los mismos moldes desde donde se les concibe como profesionistas por parte de los empleadores (Benassini, 2001). 
iniciativa colectiva por realizar una serie de estados de la cuestión de lo que hasta ese momento se había realizado auspiciado por la Asociación Mexicana de Investigadores de la Comunicación. Ambos esfuerzos fueron publicados (Fuentes Navarro, 1988: Sánchez Ruiz, 1988) y con ellos se posibilitó hacer una revisión de los caminos andados, una aproximación a los modos, temas y objetos, pero también propicio que se pudiera expresar lo que en esos momentos se consideraban como las agendas pendientes y urgentes por investigar. El mismo Fuentes Navarro continuó realizando la sistematización y difundiéndola a través de nuevas publicaciones (Fuentes Navarro, 1996), así como otros investigadores (Sánchez Ruiz, 1992; Orozco, 1992).

Estas miradas que se conformaron permitieron dar elementos para comenzar a hablar del campo académico de la comunicación pues si bien había divergencias y diferencias, también había una serie de elementos que se compartían. También ratificaba el hecho de insistir en el proyecto sociocultural del conocimiento en comunicación pues al reconocer que no todo era lo que se daba en las instituciones educativas, ni en la mera docencia, sino también lo que sucedía con los actores sociales del campo, y la importancia de generar conocimiento, se comenzo a pensar una serie de condiciones, obstáculos, retos por encarar y superar y que se encarnarían como parte del proyecto que se difundía, y configuraba, de lo que tocaba hacer, o lo mínimo para ingresar y tener presencia en el campo. Así mismo, se hizo evidente la fuerte tendencia de que el campo era, $y$ ha sido, los medios de comunicación, pues se encuentra, y se seguirá registrando, la enorme atención que se les daba, dejando otras instancias y objetos de lado.

Las sistematizaciones, las agendas y los mapas que se generaban, eran síntomas, pero también los procedimientos y lineamientos de lo que estaba sucediendo y de lo que tocaba hacer dentro de la emergente comunidad académica; fueron parte de sus sistemas de comunicación, de las operaciones de observación que propiciaban y una forma de generar un imprinting cultural dentro de los nuevos investigadores de la comunicación.

\section{Para ver las miradas sobre las miradas.}

Comenzar a pensar a la comunicación desde los paradigmas y desde la noción del campo académico de la comunicación fue un acto de creación, en el sentido de colocar el pensamiento de lo que se entendía 
por comunicación, e investigarla, dentro de una sociología del conocimiento. Fue el intento de pensarla desde sus determinaciones socioculturales y, por ello, pensarla como un programa de investigación, y comenzar a historiar su desenvolvimiento como tal $y$, por tanto, evitar un andar ciego y girar para que fuera la heurística de sus propios programas los que determinaran la selección de problemas considerados como fundamentales y básicos para su continuidad y desenvolvimiento (Lakatos, 1983: 145).

Pensar de esta manera a la comunicación bajo las orientaciones y trayectorias que fueron parte de los marcos por impulsar el quehacer de la investigación como generadora de conocimiento era una respuesta a algo que se iba reflexionando, tiempo atrás dentro del ámbito de la ciencia y las ciencias sociales en particular, es decir, las avenidas que se iban abriendo a partir de las propuestas de realizar una sociología de la ciencia. Este punto es importante para comprender el contexto social y textual desde donde las personas que comenzaron a mirar a la comunicación, pues de esta manera asumieron una posición, y desde las cuales gran parte del resto de la comunidad las retomó para intentar dar coherencia a su propio pensar y obrar (Bourdieu, 1997: 13). Si bien para ello hay que hacer toda una indagación mucho más amplia y exhaustiva para comprender el contex to y las múltiples relaciones que se realizaron para realizar la misma producción del campo, es importante señalar algunos elementos, pues parte de lo que ahí se configuró conformaron la mirada para mirar al campo académico de la comunicación.

En la misma década cuando se funda la primera carrera de comunicación en México se dieron una serie de acontecimientos que fueron claves para el giro que tomarían las ciencias sociales: los sesentas. Momento de quiebres y de continuidades, los sesentas se vivieron con intensidad y a distintos niveles, internos y externos, que afectaron la visión de lo que era hacer ciencias sociales y la visión que tenían de si mismas, y que durante los primeros años generara tanto una actitud de recelo y rechazo de unos, la mayoría, así como entusiasmo y aceptación de otros, que en un principio eran minoría. Los sesentas fue un momento de giros en lo económico, lo político y lo social que trasladaron y cuestionaron los principios epistemologicos de la ciencia tradicional, y se tornó diversa y relativa. Es decir, algo se dejaba de ver en la vida social que implicaba dejar de conocerla, y que al acercarse a ella, podría generar otro tipo, o más, conocimiento de lo social. Es por ello que se retomó aquellos esfuerzos de ciertos 
pensadores de la ciencia social de principios de siglo que dentro de su pensar lo social, pensaron la manera como se generaba conocimiento de lo social.

A principios de los setenta, Barry Barnes expuso que ante el crecimiento acelerado de la ciencia, comenzaba a ser reconocida como una institución importante para las sociedades de ese momento, cobraba reconocimiento tanto económico como cultural, pero que apenas comenzaba a ser examinada su estructura interna, y su relación con la sociedad (Barnes 1980,11). Barnes expresaba que pese al interés que comenzaba a suscitar, y el crecimiento de perspectivas y procedimientos de explicación, la atención hacia el proceso de institucionalización de la ciencia era poco atendida, algo que a finales del siglo XX Peter Burke volvería a expresar (Burke 2000). En ese contexto, Barnes enfatizaba la creciente influencia de la obra de Thomas Kuhn que apareció en $1962^{\circ}$. Si bien Thomas Kuhn no fue el único científico que trabajo esto, ni fue ajeno a críticas desde entonces y hasta el presente, representó un espíritu de época de varios que estaban cuestionando fuertemente el quehacer de la ciencia y del investigador que se proclamaba como "objetivo e imparcial" (Kuhn 1980, 79), y que al mostrar como había un desajuste entre sus presupuestos y la forma como en realidad actuaba y era influido por una serie de procesos institucionales, comunitarios, sociales y culturales, la ciencia se manejaba más en un orden mitológico que de aspiraciones metafísicas. Dentro de las polémicas que suscito Kuhn, en gran parte se fue confluyendo en el sentido de que lo social y lo cultural tenían un peso importante, $y$, para dar cuenta de ello, se requería un acto de selección para mirar y organizar la perspectiva desde donde se observaba el desenvolvimiento de la ciencia.

"Barnes lo expresaba así: "La profunda influencia que Thomas Khun ha comenzado a ejercer sobre los sociólogos obedece a la comprensión que proporciona de la investigación como proceso social. Dicho en términos sociologicos, la tesis de Khun es que dentro de las disciplinas particulares se mantienen modelos esotéricos de procedimientos de interpretacion, y ellos brindan la base para la práctica y la evaluación de la investigación. La mente racional abierta no es ef instrumento ideal para reconocer una verdad cientifica, como sostendrían los filosofos y los sociólogos empiristas, sino que es esencial un marco de referencia conceptual y de procedimientos elaboradamente preparado. Al señalar los supuestos paradigmáticos de los científicos y el modo en que ellos definen a los grupos cohesivos de investigaciones, Kuhn ofrece un enfoque sociologico del proceso de investigación" (Barnes, 1980: 62). 
En esta época, la misma sensación creció por distintos motivos y contextos, y se dieron diferentes respuestas. Una constelación de corrientes, autores reaccionaron y sus reflexiones comenzaron a ser parte de los nuevos derroteros que se buscaban para entender y ejercer la actividad de la investigación. No sólo fueron filósofos y científicos quienes lo hicieron, sino también fueron sociólogos y antropologos. Son los momentos de la aparición de las obras de Peter Berger y Thomas Luckman, de Michel Focuault, Claude Levy Strauss, Jurgen Habermas, Roland Barthes, Pierre Bourdieu, y otros más, quienes serán fundamentales para el pensamiento social de las siguientes décadas, y quienes harán un giro en la manera de estudiar la relación entre sociedad y conocimiento respecto a la manera como se había estudiado a principios del siglo XX.

Una manera de comprender el espíritu de época puede verse a través de la manera como algunos de ellos comenzaron a escribir sus propuestas. Un ejemplo lo podemos encontrar en la manera como Pierre Bourdieu emprendió el trabajo de realización del libro $\mathrm{El}$ oficio de sociólogo en 1966, libro que se convertiría como un referente necesario para emprender una acción indagatoria de lo social en distintos ámbitos académicos en América Latina al ser publicado a mediados de la década de los setentas. Varios años después, Beate Krais, la traductora del libro al idioma alemán, le hace una entrevista sobre el motivo por el cual se emprendió esa obra, Bourdieu le responde que había una razón pedagógica, escribir un manual de investigación, pero había otra razón más amplia. Expresa:

"Sí. Estaba la intención pedagógica, pero también la voluntad de hacer un balance de una decena de años de trabajo sobre el terreno, en etnología primero, y en seguida en sociología. Yo había trabajado mucho en Argelia con la gente del Instituto de Estadística y tenía la impresión de que habła puesto en práctica una metodología que todavía no había encontrado su explicitación; la impresión de que era muy necesario hacerla explícita se encontró reforzada por el hecho de que en este momento era el extremo de la invasión "lazarsfeldiana" en Francia. Lazarsfeld, alrededor de los años sesenta vino a París y dio en la Sorbona cursos solemnes a los cuales creo que asistieron todos los sociólogos franceses, excepto yo, y esto de una manera deliberada: yo pensé que, simbólicamente, no tenía que meterme en la escuela de Lazarsfeld (era suficiente leer sus libros). A través de técnicas interesantes, que era necesario aprender, y que yo había aprendido, imponía otra cosa, es decir, una epistemología implícita de tipo 
positivista que yo no quería aceptar. Y esta es la verdadera intención del Oficio" (Bourdieu 1997a: 42).

Y más adelante señala cómo veía el panorama de la sociología de esos momentos:

"En aquel momento yo veía dos errores opuestos contra los cuales la sociología debía definirse: el primero, que puede llamarse teoricista, estaba simbolizado por la Escuela de Frankfurt, es decir, por gentes que, sin hacer investigación empírica, denunciaban por todas partes el peligro positivista (Goldman era el representante en Francia de esta corriente). La segunda, que podemos llamar positivista, esa simbolizada por Lazarsfeld/Adorno, a propósjto de lo cual yo escribí una nota en el apéndice de La Distinción. Contra estas dos orientaciones se trataba de hacer una sociología empírica fundada teóricamente, una sociología que puede tener intenciones críticas (como toda ciencia), pero que se debe realizar emṕricamente" (Idem: 42-43).

Y cuando se le pregunta sobre las epistemologías que estaban al alcance de la mano, Bourdieu expresa que en esos momentos sólo tenía su propia experiencia, la cual lo había llevado a la importancia de construir el objeto y que en ello intentó trasladar a las ciencias sociales la tradición epistemológica representada por personalidades como Bachelard, Canguilhem y Koyré, de la cual también abrevó Kuhn y que en esa época era poco difundida en Francia, y que tiene en común "la primacía dada a la construcción: al acto científico fundamental es la construcción del objeto: no vamos a la realidad sin hipótesis, sin instrumentos de construcción. Y cuando se le cree desprovisto de todo presupuesto, se le construye aun si saber y, casi siempre, en este caso, de manera inadecuada. En el caso de la sociología esta atención a la construcción se impone con una urgencia particular porque el mundo social se autoconstruye en cierto modo; nosotros estamos habitados por preconstrucciones" (Idem: 44). La postura fue realizar una sociología que rompiera con las pre nociones, la teoría espontánea, tanto porque la mayoría de las investigaciones estaban construidos mediante ellas, y avaladas por las comunidades científicas ${ }^{\text {to }}$.

${ }^{10}$ Esta postura habla de la necesidad de hacer una sociología de la sociología para "poner en duda la ilusión del saber absoluto que es inherente a la posición del sabio, y la forma particular que esta ilusion toma según la posición que el sabio ocupa en el espacio de la produccion cientifica" (ldem: 47-48), tarea que 
Destacar a Thomas Kuhn y a Pierre Bourdieu no es gratuito: ambos han sido considerados como dos de los autores que han dado pautas para intentar realizar un acercamiento sociocultural a la producción del campo académico de la comunicación, como más recientemente lo ha sido Anthony Giddens con su teoría de la estructuración (Fuentes 1998a). Si bien no son los dos únicos autores que han influido, destacan en la manera como se les ha retomado para crear pautas de un paradigma institucional del desarrollo del campo académico de la comunicación.

\section{Para mirar al campo académico de la comunicación. Mi- rar las miradas.}

Dentro de la producción de investigaciones de comunicación en México hay un dato que llama la atención: durante el periodo que va de 1985 a 1994 el eje de la producción tuvo un sensible deslizamiento hacia una zona del país que anteriormente había tenido una presencia limitada y marginal: Ja región centro occidente. Es decir, desde la aparición de los primeros trabajos de investigación sobre la comunicación en el país, la mayoría se producían en la ciudad de México, y el resto de las ciudades tenfan una participación insignificante; pero en los años indicados en la región centro occidente se sucedió algo que un $29.5 \%$ de la producción total se produjo en esa región, y particularmente en dos ciudades Guadalajara y Colima (Fuentes Navarro 1996a: 30).

Raúl Fuentes Navarto lo expresa así:

“... durante la segunda mitad de los ochentas se crearon nuevos centros de investigación en algunas universidades, donde encontraron apoyo investigadores formados en doctorados en ciencias sociales del país o del extranjero, con perfiles reconocibles por las instancias oficiales de impulso a la Investigación científica (como el Sistema Nacional de Investigadores), y con vocación para una nueva vinculación docente, orientada más hacia el postrado que hacia las licenciaturas. Buena parte de esa "renovación" del campo académico de la comunicación en México, como se detallará más adelante, se

realizaría en su trabajo Homo Académicus, donde intentará objetjvar la mirada objetivadora de los investigadores, de él mismo, y de esta manera, dar cuenta de la manera como el campo acadérnico se produce y se relaciona con otros campos. 
situó en la región centro occidente, específicamente en Guadalajara y Colima (Fuentes Navarro 1996a: 27).

Las ciudades de Guadalajara y Colima se erigieron como dos espacios para pensar la comunicación y generar productos de conocimiento. Ambas acciones no sólo alteraron la distribución geográfica de la producción y generación del conocimiento sobre la comunicación, sino que pudieron dar pautas orientadoras para la configuración del campo acađémico de la comunicación. Dos ciudades que representaban sendos centros de investigación donde pudieron intervenir varios actores de conocimiento formando equipos de trabajo, elaborando programas de reflexión e indagación, y, también, formando redes y comunidades de investigación dentro y fuera del país. Fue una generación que sobre las bases de fundación e institucionalización del campo académico de la comunicación en México, decidieron tomar el reto de avanzar hacia su reflexión epistemológica, por diferentes vías, procedimientos y programas, intentando dar visibilidad a la comunidad y ganar terreno en su autonomía y legitimación.

No fueron los únicos que lo hicieron, pero en ellos podemos encontrar gran parte de los trazos y orientaciones que siguió gran parte de la investigación de la comunicación en México, la síntesis de una serie de factores externos e internos para que ello pudiera ser, y los horizontes desde donde en la actualidad se pretende pensar a la comunicación. Su visión, impulso y vitalidad, orientaron a muchos en el campo, dialogaron con otros campos y otros entornos geográficos más amplios.

Campos de producción de conocimiento y de sentido de la comunicación.

Para entender lo sucedido en la ciudad de Guadalajara hay que tener en cuenta dos ámbitos académicos importantes: lo que aconteció en la Universidad de Guadalajara y en el ITESO. Por la coincidencia, amistad y relación de los miembros de ambas instituciones, lo producido en ambas instituciones, los acercaron en algunos objetivos, procedimientos, productos que en muchos casos pareciera que más que las instituciones era una sola comunidad de la ciudad quien lo había realizado. Incluso, andado el tiempo se le ha llegado a denominar "el grupo de Guadalajara" (Martín Barbero, 2000: 15).

En el caso de la Universidad de Guadalajara hay un hecho particular: la fundación del Centro de Estudios de la Información y la Comunicación (CEIC). Después de varios procedimientos. en 1986 
se fund6 el CEIC, "considerando que éste cubría espacios comúnmente relegados por otras instituciones de educación superior, las que ante la urgencia de dar respuesta a los requisitos impuestos por la atención a una demanda estudiantil masiva (y en crecimiento) y por la falta de recursos humanos, se veían limitadas para llevar a cabo tareas de investigación y postgrado" (Arredondo, 1997: 18). En sus reflexiones sobre la manera como se fundó el CEIC, Pablo Arredondo, uno de los ideólogos y fundadores del proyecto, expresa que fue concebido "como una alternativa académica de avanzada en donde se llevaría a cabo lo que escasamente se realizaba en otras universidades". Es decir, la alternativa era evitar seguir los mismos pasos "ya andados" por otras universidades y evitar sus mismos problemas. Para ello, había cuatro pilares que eran la investigación, la educación en postgrado, la difusión científica y la vinculación académica. Con objetivos varios como los de ser una opción diferente que permitiera el análisis crítico de la comunicación social en el país, y con particular atención a su propio entorno; incidir en la producción y sistematización del conocimiento sobre la comunicación mediante estudios e investigaciones; formar a nuevos agentes del conocimiento; y convertir al CEIC "en un centro de difusión del conocimiento científico de las disciplinas que inciden en la comunicación, por medio de la realización de eventos académicos y la producción de materiales pertinentes" (Idem.). Dos puntos a destacar: la investigación fue concebida con un carácter multidisciplinar y se conformaron tres líneas de investigación: las relaciones de la comunicación con el poder político, la economía y la cultura.

Estas visiones son importantes porque fueron en gran medida la manera no sólo como se investigó a la comunicación, sino al mismo campo. Esta visión sobre la comunicación tuvo una difusión debido a la creación de unos cuadernos monográficos bajo el nombre de Comunicación y Sociedad, que posteriormente se transformaría en una de las revistas más reconocidas, así como la publicación de varios libros y documentos". Es particularmente sugerente la manera como

"Uno de los enfoques predominantes empleados, y, quizá, con mayor difusion, fue el histórico estructural desde donde se hicieron algunos estudios sobre los medios de comunicación (Arredondo y Sánchez Ruiz 1986), así como al estudio mismo de la situación y desarrollo del campo académico de la comunicación (Sánchez Ruiz 1986), una propuesta metodológica para la investigación de la comunicación (Sánchez Ruiz 1992a). De hecho, al realizar un balance de los estudios de la comunicación, Enrique Sánchez Ruiz. uno de 
Arredondo expresa la manera como se comenzó a trabajar, una vez que el CEIC fue establecido:

Los tres investigadores titulares que integraron la planta original asumieron, además de las obligaciones académicas, responsabilidades paralelas en la dirección, en la coordinación de investigación, en la de enseñanza y en la difusión. De manera simultánea, se puso en marcha el plan para vincular al nuevo centro con las más importantes instituciones universitarias dedicadas a la enseñanza y a la investigación de la comunicación en el país y en la medida de lo posible en el extranjero. No debe olvidarse que la apuesta de los propulsores del CEIC fue la de convertir a la Universidad de Guadalajara en un referente importante de la disciplina tanto en la región como a nivel nacional. En otras palabras, los fundadores mantenfan una conciencia clara en materia de descentralización educativa, en un contexto que ha privilegiado la concentracion de los recursos y las decisiones de manera exagerada (Arredondo, 1997: 21-22).

Así es como el CEIC generó un programa de investigación que implicaba retomar elementos institucionalizados ya por el campo, como incidir en él, mediante la generación de cierto tipo de conocimiento, y por tanto cierta concepción de hacer ciencia, relacionarse con instituciones y comunidades, orientarlas, abanderarlas, convertirse en centro y eje de referencia e influencia, con una visión regional, nacional e internacional. Algunos de los investigadores del CEIC participaron en distintos grupos de investigadores a nivel local (AMIC, CONEICC) e internacional (ALAIC), e incluso participaron asumiendo puestos directivos, lo cual propició tres cosas: un acercamiento a diferentes redes y comunidades académicas de la comunicación; una mayor difusión de sus trabajos y propuestas, así como el intercambio y difusión de otras que venían del exterior, y la organización de una serie de foros y encuentros que fueron importantes dentro del trabajo de conformación del campo académico de la comunicación, al conducir a la realización e intercambio de ciertos estudios e investigaciones sobre los medios de comunicación, así como de diagnósticos sobre lo que se ha investigado

los principales investigadores, y fundador, del CEIC, veía en 1997 que la comunicación había tenido una tendencia a la sociologización (Sánchez Ruiz , 1997: 63). 
de ellos. Es el caso de lo que sucedió en la Cuarta Reunión Nacional de Investigadores de la Comunicación ${ }^{12}$ que convocó la AMIC en 1987 en la ciudad de Guadalajara, y donde la "idea era reflexionar colectivamente, a partir de las ponencias que se presentaran, sobre la práctica social y profesional del investigador de la comunicación en México de hoy. También se pensaba llegar a un diagnóstico de tal práctica para a la vez arribar a propuestas (a nivel indicativo) que la guiaran en el futuro cercano" (Sánchez Ruiz, 1988a: 9).

El caso del ITESO es diferente, pero varios elementos correrán en paralelo a lo acontecido con la Universidad de Guadalajara. De las múltiples cosas con que el ITESO ha contribuido para ser un espacio académico reconocido en el ámbito de la comunicación en México y América Latina, quisiera destacar la presencia de Raúl Fuentes Navarro y su obra reflexiva. Además de ser desde hace un buen tiempo uno de los principales pensadores sobre la enseñanza de la comunicación en el país y en Latinoamérica, su obra de sistematización de la investigación de la comunicación en México ha sido fundamental para dar visibilidad al campo académico y crear los mapas para su autonomía y legitimación.

Como sucedió con Bourdieu que al comenzar su trabajo de producción de conocimientos tenía su propia experiencia y una epistemología que provenía de la filosofía de la ciencia y que intentó trasladar a las ciencias sociales, Raúl Fuentes contaba con su propia experiencia como docente, profesional e investigador de la comunicación cuando comenzó a pensar sobre la situación de la investigación de Ja comunicación en México. Su participación en algunas asociaciones nacionales (CONEICC, AMIC), e internacionales (ALAIC, FELAFACS) contribuyeron a ello.

Por un lado, fue quien recibió el Centro de Documentación del CONEICC, el más completo del país, en 1983, y con ello pudo acceder a los primeros intentos de sistematización sobre la investigación

12 Además de que Ia mayoría de las ponencias se publicaron en un libro colectivo (Sánchez Ruiz 1988), y con lo cual se pudo contar por primera vez con una gama de estados de la cuestión sobre to que se había investigado de los principales medios de comunicación en México, o por lo menos fue más amplia su difusión de otros intentos que se habían realizado anteriormente, como aquella iniciativa realizada por la Universidad Autónoma de México bajo la colección de La Comunicación Social en México, sirvió de plataforma para nuevas actualizaciones o mayores profundizaciones de estados de la cuestión hasta mediados de la década de los noventas. 
de la comunicación en México que en los setentas realizaron Joseph Rota y Rubén Jara, y tener a disposición un amplio material por trabajar. También, a principios de los ochentas en algunos países (Chile, Perú, Colombia y Brasil) realizaron esfuerzos de sistematización de la investigación, coordinados por la ALAIC, y Fuentes Navarro, al participar dentro de esos esfuerzos, comenzó a hacer lo propio para el caso de México. Más adelante continuaría haciendo lo mismo, tanto por una inquietud personal, como por su participación, y en ocasiones a solicitud de asociaciones latinoamericanas.

A mediados de los ochentas Raúl Fuentes comenzó a trabajar en la sistematización, algunos resultados los presentó en la ya mencionada Cuarta Reunión Nacional de Investigadores de la Comunicación de la AMIC en 1987, y al año siguiente aparecería el libro donde aparecía una sistematización de documentos que cubrían un periodo de 1956 a 1986, y además incluía una descripción del universo de documentos sistematizados, clasificados y analizados, así como una breve reconstrucción histórica. En la introducción, Fuentes Navarro escribía:

"Pero la investigación de comunicación tiene que ver también con las determinaciones que le impone la formación social en que se desarrolla, con las características de los sujetos que la practican y de las instituciones en que se insertan, con los programas de formación académica y los recursos invertidos en ella, con el financiamiento de proyectos y el reconocimiento social de la importancia de sus productos, con las articulaciones que establece con diversos agentes sociales para la selección de problemas de aplicacion de resultados y con los canales de difusión de sus aportaciones... La investigación de comunicación en México, por estas y otras dimensiones y aspectos que la cruzan y constituyen, es un conjunto de prácticas sociales complejas. cuya dinámica es difícil de desentrañar, pero que, en el momento actual de su propio desarrollo, exige un esfuerzo serio de sistematización y clarificación de sus condicionamientos, avances y límites" (Fuentes Navarto 1988, 13).

En estas pocas frases, Fuentes Navarro exponía no sólo la condición de muchos profesionales del mundo académico de la comunicación en el país, sino la importancia de contar con los recursos para generar información. En ese sentido, se veía necesaria una serie de elementos y factores que permitieran su formación como agentes 
de conocimiento, e instrumentos para orientarla y emplearla. Por eso planteaba como necesario e importante, para la continuidad de la misma investigación de la comunicación en esos momentos, un trabajo como el que proponía.".

Raúl Fuentes sintetizaba una experiencia individual y colectiva del momento y se dirigía a poner las bases para reconocer a una comunidad que pasaba "desapercibida". Tres años después, en 1991, publicó otro libro donde proseguía por la misma línea pero con otra intención. El mismo Fuentes Navarro exponía que uno de los objetivos era "exponer una panorámica general del proceso de constitución en México de un campo de estudio especializado en la generación de conocimiento sobre la comunicación (Fuentes Navarro, 1991: 15), y lo hacía a través de la recuperación sistemática de documentos y un trazado del proceso historico de la investigación de la comunicación. La visión campal se insertaba y se hacía buscando a una comunidad de investigadores, siguiendo la propuesta de Kuhn sobre la conformación de un paradigma mediante una comunidad académica, y con ello incorporaba una reflexión que proviene de una tradición de la filosofía y sociología de la ciencia, cosa que continuará explorando para años después realizar su tesis doctoral, y lo realiza considerando la importancia de una visión histórica estructural, que complementara la suya, porque expresaba que después de tres décadas de producción de conocimiento, bajo ciertas condiciones históricas determinadas, se podía identificar a una naciente comunidad de investigadores.

13. La misma sistematización reforzaba las conclusiones que anteriormente habian realizado Rubén Jara y Joseph Rota, y que era el sentimiento de algunos en la reunión de la AMIC aludida anteriormente: carencias de prioridades de investigación, de orientaciones teóricas y metodologicas, de infraestructura y apoyo para la investigación, de agentes preparados y capacitados y dedicados a investigar. Es por ello que las mismas conclusiones de Fuentes Navarro iban por la línea de continuar documentando y sistematizando lo que se realizaba en la investigación de la comunicación en México, así como investigar sobre las características de la misma como una práctica social, en relación con lo que sucedía en otros países, y con ello, "posiblemente, se avance más en la construcción de una responsable y solida comunidad científica. que tenga mucho más que aportarle al pafs" (Fuentes Navarro. 1988: 60).

"Expresaba que era necesario considerar las condiciones estructurales que ha determinado ciertas prácticas científicas, que tanto la han limitado en cuanto a su poca promoción y apoyo, ciertas orientaciones téricas y metodologicas, como en la formación de agentes capaces y capacitados y en condiciones de 
Ante un clima generalizado en América Latina que venía coincidiendo desde principios de los ochentas de tener marcos orientadores que permitieran superar las visiones fragmentarias, ideológicas y en disputa, y en momentos de fuertes crisis y transformaciones que iban colocando a la comunicación en el aentro de una nueva racionalidad económica y política, como otros investigadores latinoamericanos, Raúl Fuentes intentó hacer un trabajo a ese nivel en 1992. El mismo título expresaba la visión: Un campo cargado de futuro, y el supuesto que lo guiaba, expresado por el autor, era que "la construcción de mapas orientadores ante la creciente complejidad del campo es prerrequisito importante para la generación de opciones fundamentales más claras y para el reconocimiento de los antecedentes, fundamentos y necesidades de desarrollo del pensamiento y la acción latinoamericanos sobre la comunicación en la última década del siglo XX" (Fuentes Navarro, 1992: 7). El libro era una apuesta por la continuidad de conformar un campo académico, y esto estaba bajo dos supuestos: la visión utópica de no renunciar al trabajo, y que este estaba en el futuro. Es importante ver como Fuentes Navarro inicia sus conclusiones:

Un texto como este no puede tener conclusiones. En primer lugar, porque precisamente su proposito principal es "abrir el horizonte tưuro" del campo académico de la comunicación en América Latina; en segundo lugar, porque los "balances" y juicios autocríticos se han tomado más como punto de partida que como objetivo. Además, porque si bien puede ya hablarse de una densa y compleja trama histórica del estudio de la comunicación en Latinoamérica, tres décadas no son suficientes para considerar que sus pautas, límites y tendencias están plenamente establecidas. De manera que, para cerrar la larga aunque incompleta revisión que hemos propuesto, no queda sino señalar algunas líneas de trabajo sobre las cuales habrán de desarrollarse los avances más productivos del campo académico de la comunicación en la última década del siglo XX (Fuentes Navarro, 1992: 223).

ejercerla con rigor y sistemáticamente, y que la colocaban en una triple marginalidad: la primera, práctica científica como práctica social considerada como pertinente y necesaria; la segunda, las ciencias sociales dentro del universo cientifico: $y$ la tercera, la comunicación dentro del mundo de las ciencias sociales. 
Los ochentas fue visto como una década de crisis, pero que para la investigación de la comunicación en el país representó una incipiente renovación, un impulso, crecimiento y diversificación que hacía más compleja la visión general o creación de mapas orientadores. Esto también sucedía en América Latina. Las mismas conclusiones de Fuentes Navarro iban por esa línea: si bien no era fácil, y menos a través de la tarea de un solo autor, de crear mapas orientadores sobre el pasado del campo, en ese presente, en los noventas lo era más todavía. Tanto por los cambios bruscos, desconcertantes, ambiguus, cargados de incertidumbres de los procesos económicos, políticos, sociales y culturales, el mismo hacer y quehacer de los medios de comunicación, la explosión de escuelas de comunicación, y, también la creciente y diversificada producción de conocimientos.

En 1992, junto con Enrique Sánchez Ruiz, publicó un texto donde se incluía un apartado en el cual se hacía una serie de indicaciones y reflexiones sobre lo "que sabemos", es decir, aquellos temas que tienen como objeto a los medios de comunicación, en los cuales ya se ha generado conocimiento, e, incluso, sobre lo que aún hay una serie de vacíos ${ }^{1.5}$. Entre los cambios estaban varias cosas que es importante destacar: hubo un sensible crecimiento de documentos, pues en siete años se duplicó, y más, lo hecho en los treinta años anteriores; como ya lo expresamos anteriormente, fue sensible la aparición de nuevos lugares para la producción de investigación (Guadalajara y Colima); la tendencia de ver a los medios de manera general se hacía más difícil de identificar; apareció la vertiente cultural de los estudios de la comunicación, aunque también desde un enfoque sociocultural se abordaron las determinaciones económicas, políticas y tecnológicas; aparecieron nuevos investigadores y la presencia de ciertos centros de investigación (Programa Cultura de la Universidad de Colima, CEIC de la Universidad de Guadalajara, PROIICOM de la Universidad

15. Al final del apartado expresaban: "Poco a poco, haciendo de lado los intentos "esencialistas" de explicacion, entendemos los fenomenos y los procesos de comunicación masiva como complejos y multidimensionales, que operan en la sociedad a diversos niveles de generalidad social. con diversos tipos de arliculación, y por lo tanto de interacción, con la economía, las estructuras de poder, la cultura y la estructura y movimientos sociales. Sin embargo, no hemos sido capaces, todavin, de integrar todas esas dimensiones, niveles, articulaciones y mediaciones en marcos teóricos coherentes, que generen más y mejores preguntas concretas de investigación concreta" (Fuentes Navarro y Sánchez Ruiz, 1992: 33). 
Iberoamericana) fueron fundamentales para la divulgación, mediante sus revistas o líneas editoriales, de enfoques, teorías, autores, que fueron configurando las vertientes más sólidas y recurridas en los primeros años de los noventas ${ }^{16}$.

Sin embargo, y pese a todo ello, señalaba que poco se había aportado para el conocimiento de la comunicación social, pues se continuaba aislando los elementos de la comunicación sin detenerse a entenderlos para pasar a explicar los factores socioculturales, que son más propios de otras disciplinas de lo social, Fuentes Navarro señalaba que esto era visible también en los programas de teorías de la comunicación, y que la investigación parecía avanzar mediante una ruptura con la vida y las prácticas profesionales, lo que reforzaba la hipótesis de una desarticulación múltiple con implicaciones para la investigación de la comunicación:

En primer lugar, esta hipotética tendencia a la disolución disciplinaria de la comunicación puede verse como más positiva que negativa, y sería entonces cuestión de desarrollo futuro el incremento de atención sobre las explicaciones comunicacionales de los más diversos fenómenos socioculturales, así como el avance en la integración teórica-metodológica de los marcos apropiados para ello. También puede verse una ventaja relativa de los investigadores de la comunicación el reconocimiento de que lo que en tiempos más dogmáticos se despreciaba como eclecticismo, no significa renuncia al rigor ni al sentido de la investigación. Por postdisciplinarización entiendo este movimiento a la superación de los límites entre especialidades cerradas y jerarquizadas, $y$ al establecimiento no de un postmodernismo donde nada tiene sentido, sino a un campo de discursos y prácticas sociales cuya legitimidad académica y social dependa más de la profundidad, extensión, pertinencia y solidez de las explicaciones que produzca, que del prestigio institucional acumulado por un gremio encerrado en si mismo (Fuentes Navarro, 1996: 24-25).

16

Fuentes Navarro lo sintetizaba de la siguiente manera: "Las culturas contemporáneas. las mediaciones histórico-estructurales de los medios de difusion y las prácticos sociaies de comunicación desde la recepción de mensajes, se han convertido así en los núcleos más fuertes de impulso a ciertos enfoques que no por coincidencia se centran en los trabajos de investigadores más reconocidos nacional e internacionalmente" (Fúentes Navarro, 1996: 21). 
Estas reflexiones, junto con las aportadas en su tesis de doctorado (Fuentes Navarro 1998), le hacían expresar que con todo y los procesos de institucionalización, no se había logrado conformar una matriz disciplinaria propia de la comunicación, y, además, "al margen de la institucionalizacion disciplinaria del campo, se han incorporado elementos cognoscitivos que rechazan la pertinencia de ésta, que enfatizan la importancia de la metodología para la construcción del conocimiento, e implican una reconfiguración del sentido de las prácticas académicas ante un entorno (nacional e internacional) cambiante, amenazante, y que parece exigir una redefinición radical de las relaciones universidad-sociedad, en una conjunción de cambios estructurales (de diversas escalas) y epistemológicos (esquemas interpretativos específicamente cientificos)" (Fuentes Navarro, 1997: 47). Es decir, aparecieron otras opciones paradigmáticas que implicaban propuestas de desarrollo del campo académico de la comunicación (Vasallo de Lopes y Fuentes Navarro 2001), y las consecuencias puede ser el alejamiento de la investigación en relación a la formación de profesionales y la fragmentación.

Hacia las culturas contemporáneas. Lo diverso, lo múltiple y lo complejo.

A diferencia de lo sucedido en la ciudad de Guadalajara, en el sentido de que fueron dos instituciones donde se desarrollo un programa de conocimiento, en el caso de la ciudad de Colima sólo fue un centro de investigación que se fundó en la Universidad de Colima: el Programa Cultura (PC), del Centro Universitario de Investigaciones Sociales (CUIS).

El Programa Cultura fue creado en 1985 bajo la dirección de Jorge González Sánchez, quien, junto con Jesús Galindo Cáceres y Gabriel González Molina lo pusieron en funcionamiento. A más de diez años de fundado el PC Jorge González expresaba sobre su fundación:

Para mediados de los años ochentas, con un grupo de colegas que también estaban terminando la formación doctoral, fundamos en la Universidad de Colima el Programa Cultura, como espacio de documentación y análisis permanente de las dinámicas de la cultura en el país... Concentrados inicialmente en tres áreas (industrias culturales, cultura urbana y frentes culturales) los estudios sobre religión y comunicación popular, las identidades culturales de barrio, las ferias y rituales, la memoria colectiva y 
cultura urbana y finalmente el melodrama televisivo, ocuparon nuestra atención durante cerca de diez años, pero la apuesta no sólo se hacía por la producción de conocimientos. En esa década, también se quiso apostar por la transformación de algunas de las condiciones de producción de esos conocimientos (González, 1997: (39).

El centro fue fundado en una institución universitaria que pretendía apostar por la generación de conocimiento bajo un programa de investigación que para el momento era novedoso, incipiente y que implicaba una visión transdiciplinaria de lo social a partir del estudio de lo que se denominaba como "culturas contemporáneas". Tres investigadores estaban al frente de cada una de las líneas de investigación y su Jabor era ambiciosa: no sólo producir conocimientos mediante proyectos de investigación en cada una de las líneas mencionadas, sino abrir un espacio de difusión de autores, temáticas y enfoques sobre las culturas contemporáneas, y la realización de todo ello tanto en vínculo con comunidades e instituciones nacionales y extranjeras, pero formando redes de investigación, con lo cual se pretendía apostar a la formación de agentes de conocimientos en distintas ciudades del país. Pero no sólo fue la apuesta por generar conocimiento, sino por responder a las visiones que sobre la comunicación y el pensamiento social que se tenía en el momento, y producir conocimiento propio, desde marcos que las mismas realidades concretas (internacionales, nacionales y locales) exigían para hacerlas entendibles y abordables.

El ideólogo, gestor, fundador y director del PC fue Jorge González, por lo que es importante acercarnos a las razones por las que comenzó a estudiar a los Frentes Culturales en el PC, y a partir de ello podemos tener elementos del panorama ante el que reaccionó, y parte de las Íneas y visiones que se realizaron en Colima. Expresa Jorge González:

"Cómplice y participante en varias maneras del panorama trazado, un breve repaso sobre mi propia experiencia nos puede dar quizás alguna luz sobre el tema. Desde 1976 en la Universidad Iberoamericana comencé a estudiar la sociedad mexicana haciéndole preguntas desde la cultura, primero en comunidades campesinas y su relación cultural con la sociedad mayor... y luego en el estudio de la formación y caracterización de su cultura de la sierra cono habitus. En medio de estos dos primeros estudios 
en la Universidad Metropolitana-Xochimilco y dentro de la carrera de comunicación, junto con un grupo de colegas, abrimos en 1980 un espacio especialmente dedicado a este tipo de análisis: el área de investigación en "Comunicación, hegemonía y culturas subaltemas" que subsistió en plena actividad durante más de diez años... No fueron los intercambios científicos, es decir la propia dinámica del campo, sino una perturbación externa, - la represión militar en América del Sur-que mediante redes de amigos y conocidos, nos puso en contacto directo con colegas de sólida formación que vinieron a refrescar el ya de por si viciado ambiente del campo científico mexicano de mediados de los setentas, pleno de certezas de corte positivista o bien de corte que se llamaba "crítico". Con ellos llegaron a México otras bibliografías, autores, perspectivas y problemáticas que influyeron definitivamente en la reorientación de los temas de investigación y, a su vez, fueron influidos por las diversas tradiciones y corrientes que se desarrollaban en México... Fue precisamente en 1982 cuando al revisar críticamente los análisis anteriores, me di cuenta de que las categorías que había utilizado desde 1976, especialmente en la perspectiva de Gramsci, de Cirese, de Bourdieu y de Fossaert (hegemonía, subaltemidad, desniveles internos de cultura, habitus de clase, lógicas de producción) si bien habían colocado mucho más precisamente la cuestión del análisis cultural al tratar de pensar las especificidades de la sociedad mexicana, mostraban varias lagunas, sobre todo de orden metodológico. De aquí proviene la propuesta de trabajo de los Frentes Culturales en la que desde 1982 me planteé para trabajar de modo inicial con algunos procesos de religiosidad en santuarios, las ferias urbanas y la vasta experiencia cultural mexicana con el melodrama en los medios de difusión. Todos estos fenómenos tienen una el carácter marcadamente transclasista" (González 1997).

Como en otros casos vistos, el proceso no fue gratuito y fue producto de una ubicación social y de una trayectoria. A lo estudiado en la universidad (la carrera de comunicación en la Universidad Iberoamericana), se opone la experiencia que genera para realizar su tesis de licenciatura y que lo va confrontando con el universo teórico y metodológico aprendido. A la par que entra a un grupo de trabajo en la Universidad Autónoma Metropolitana Xochimilco (UAM), y que estudia su maestría y posteriormente su doctorado, ingresa, me- 
diante a otras maneras de pensar a la comunicación desde el ángulo de la cultura. Lo que asimila y adopta, es parte de un proceso que se había comenzado a dar previamente, y que era parte de algunos investigadores que tenían como uno de sus espacios de encuentro y reflexión en la UAM, y que influyó de manera determinante en los enfoques principales para estudiar a la cultura en México ${ }^{17}$.

Lo sucedido con la experiencia de Jorge González, que en cierto sentido era un sentir de algunos en su época, fueron los cimientos para la orientación del PC. Por un lado, expresa, fue causa de un

17

Gilberto Giménez señala el contexto de la siguiente manera. "Notemos, ante todo, que el interés por el estudio de la cultura como objeto de una disciplina espećfica y con una perspectiva teórico-metodológica también específica es muy reciente en México y no se rernonta a más de 20 años. Podemos afirmar que dicho interés nace muy vinculado con el descubrimiento de las obras de Antonio Gransci en los años setenta, obras que se tradujeron y se difundieron rápidamente en nuestro país al calor de la atmosfera marxista que impregnaba entonces el campo de las ciencias sociales. Pero la figura de Gramsci nos llega filtrada, en gran parte, por medio de la demología italiana, cuyo jefe de fila, Alberto $\mathrm{M}$. Cirese, fue indiscutiblemente el impulsor y catalizador inicial de los estudios culturales en nuestro país. Su primer seminario sobre las culturas populares en el Centro de Investigaciones y Estudios Superiores en Antropología Social (CIESAS), en julio de 1979, bajo el patrocinio de su entonces director Guillermo Bonfil, y el seminario subsiguiente que impartió sobre el mismo tema en ta UAMXochimilco, en agosto de 1981, pueden considerarse como hitos importantes en el desarrollo de los estudios culturales en México. Pero debe afiadirse de inmediato que el estímulo gramsciano así mediado no operó en un completo vacío. Por una parte, ya existían antecedentes importantes en cuanto a investigaciones culturales como lo demuestran los trabajos de George M. Foster sobre «cultura de conquista” y culturas tradicionales en México, y los de Vicente T. Mendoza sobre el cancionero popular mexicano (1954 y 1982). Por otra parte, ya existía un terreno abonado por la tradición antropológica indigenista y campesinista mexicana que desde tiempo atrás había logrado sensibilizar no sólo a la academia, sino también a los sectores dirigentes del país respecto a la problemática cultural de las clases subalternas. Incluso podríanos señalar cierto número de estudios antropológicos que de hecho abordaron múltiples aspectos de la cultura y contribuyeron acumulativamente a construir o reforzar algunas dimensiones de la cultura nacional -como la del nacionalismo, por ejemplo-, aunque no hayan tematizndo explfícitamente la cultura como objeto de indagación ni hayan exhibido preocupaciones teórico-metodológicas específicas a este respecto. La simbiosis entre Guillermo Bonfil y Alberto Cirese me parece emblemática e ilustrativa de esta especie de intersección entre la tradición antropológica mexicana y la demología italiana. No debe extrañarnos entonces que el terreno inicialmente más cultivado y frecuentado por la investigacion culturat en nuestro país haya sido el de las culluras populares" (Giménez 2001). 
desencanto en la forma como los estudios de la comunicacion, la sociología y la antropología, y las ciencias sociales, pensaban a la sociedad y, en particular la hegemonía, es decir, la postura y la actitud de estas disciplinas no sólo dejaban muchas cosas vacías, sino que en ocasiones adoptaban posturas arrogantes, que cuando intentaba aplicarla a su experiencia de trabajar con la cultura campesina, surgían una serie de preguntas que no habra forma de responderlas ${ }^{18}$. González expresa que lo que sucedía era que estudiaba a las culturas campesinas desde la diferencia, la distinción, como si fuera un antropólogo foráneo que mira a la cultura campesina como "los otros". El mismo González expresa que esa fue parte de la simiente de su trabajo con los Frentes Culturales (González 1987), los cuales le han servido como instrumentos de interrogación y de interpretación de "otro modo la cultura; poderme preguntar de otra manera lo que antes no me permitían los esquemas clásicos, incluso el concepto tradicional de cultura popular" (Montoya Vélez, 1992: 139), y de esta manera superar la inmediatez, las prenociones, con que trabajaban las ciencias sociales.

En este punto hay dos cosas por destacar. Una, González reconoce que en esa época recibio dos influencias: el pensamiento de Gramsci sobre el sentido común, y la de la filosofía hermenéuticafenomenologica, es decir, aquelta que se le identifica con "la sociología de lo ordinario". La segunda se refiere a la manera de emplear una teoría y metodología porque...

${ }^{18}$ Estas preguntas particularmente eran: ¿Como se conectan? $i$ Por cuáles vías? ¿Por cuáles tipos de arterias? ¿Cuáles son las fronteras, donde se tocan estas culturas campesinas (las que yo estudiaba) y las culturas dominantes? (Montoya Vélez, 1992: 135).

${ }^{10}$ Pero resulta que esos campesinos han estado ligados desde la Colonia, desde su formación como campesinos, a una cultura mayor, a una cultura urbana, metropolitana, dominante, a una cultura observante que es desde donde han sido aculturizados... Lo que sucedía era que me enfocaba exclusivamente en las formas de distinción, en estudiar la diferencia (ya se que son diferentes, ya se inclusive que pueden ser subalternas o populares), y no me preguntaba: ¿Cómo se hicieron populares? ¿Como se construyeron subalternas? ¿Por donde empieza una cultura a perder la batalla?... Hacerse estas preguntas suponía que lo popular no es un síndrome, ni la subalternidad es como un encono que la gente tiene, sino que es una relación; entonces, estudiar una relación significa analizarla relacionalmente y esto expresa tratar de entenderla desde otro punto de vista, no sólo en su otredad, sino precisamente en los puntos en que su alteridad se ve en crisis, donde su otredad se ve pegada con la otredad de otro (Montoya Vélez, 1992: 135-136). 
... la metodología es precisamente el oficio de los investigadores, es construir marcos metodológicos, estrategias de uso de técnicas, métodos para lograr objetivos pertinentes teóricamente. Yo lo llamo polifonía. Hay que reconocer muchas cosas para dar cuenta de este tipo de objetos: desde los registros históricos, trabajos con bases de datos, encuestas, métodos sociológicos de muchos tipos: cada vez más siento precisamente que es el arsenal o la riqueza práctica, el capital específico de los investigadores... Yo soy el que decide cuando y cómo entran y qué me van a decir... Es un esfuerzo por tratar de dominar las técnicas, no que éstas lo usen a uno. Por eso, no es monotécnico el trabajo. Los frentes, como objeto complejo, no se dejan aprehender de cualquier manera, se trabajan desde muchos puntos de vista y con una cantidad de técnicas que suelen ser complejas (Montoya Vélez, 1992: 141).

Con lo anteriormente expuesto, es posible considerar lo que expresará el mismo González cuando señalaba que el PC surgió ante dos situaciones: la insuficiencia de preguntas, instrumentos e interpretaciones en una época de crisis en México; al mismo tiempo, organizar y reafirmar una estrategia de estudio de la sociedad y sus movimientos ante un punto de vista que era negado por la antropología, la sociología y los estudios de la comunicación de una sociedad multidimensional y compleja de la cultura contemporánea.

Así, no había un espacio para estudiar estos procesos y fenómenos en México, ni a reconocerlos como tal, así como otro reconocimiento: el enorme centralismo y la ausencia de trabajo en y sobre las múltiples regiones del país, regiones que sufrían similares procesos de relación múltiple con un pasado, un presente en crisis, en transformación dentro y como parte de las culturas contemporáneas ${ }^{20}$.

"2) La sociología mexicana negaha el estudio de las realidades simbólicas, y ante una preocupación por las bases cconómicas y las estrategias politiciss, habían olvidado a la gente común. sus cntornos. experiencias y práclicas. y la cultura era vista. era sohredeterminada. y por lo mismo descalificada. por lo económico porque adquiría sus manifestaciones en la industria y las multinacionales. era una mercancía que era posible dar cuenta de ella por los anslisis económicos. La antropología mexicana se había enfocado a estudiar a los campesinos y las comunidades indigenas. fascinados por la visión sobre las tradiciones, el pasado. y alendiendo poco. o nada. aquelio que iba emergiendo. modificándose. mezlúndosé, moviéndose y relacionándolos con otras dimensiones simbólicas. territorios, entormos e historicidades, y que poco podían responder ante lo plural 
Las tres líneas de investigación que adoptó el PC tenían algunos antecedentes que se referían a la manera como los investigadores habian participado en otros centros de investigación dentro del estudio de la sociología de la cultura, la antropología urbana y la de los estudios de la comunicación, la hegemonía y culturas subordinadas, que al integrarse, se propuso armar un centro de investigación de alta calidad, académica que propusieran y produjeran conocimiento par el estudio y composición de los movimientos en México y América Latina, su diversidad cultural. Se pretendía entrar en contacto con investigadores, formar a otros, trabajar mediante programas de investigación, crear espacios de publicación para difundir autores, temas, objetos, enfoques, metodologías, de la manera como se estudiaba a las ciencias sociaies y las culturas contemporáneas, y que esto pudiera nutrir y ayudar a distintos centros e instituciones académicas.

Mucho de to realizado por el PC se conoció por medio de su revista Estudios Sobre las Culturas Contemporáneas (ESCC), que con el avanzar de su publicación desde 1986 se fue convirtiendo en una de las principales revistas de comunicación y estudios de la cultura en México y América Latina. Pero también, el PC fue conocido por los proyectos de investigación y las publicaciones tanto de Jorge González como de Jesús Galindo. En 1986 apareció el libro Cultura (s) de Jorge González que contenía cuatro artículos, productos de sus experiencias y búsquedas de encontrar sentido a aquellas insatisfacciones teóricas y metodológicas, y que eran parte de los antecedentes de la fundación del PC, y que se agregaba a lo que había

y complejo de las culturas mexicanas. Los estudios de la comunicación, desvalorizados por sociólogos y antropólogos, entusiasmados por las tecnologfas de comunicación y sus influencias en la vida pública, se dedicaron a encontrar a su objeto de estudio desde estas preocupaciones, pero poco se dedicaron a estudiar la manera como los medios de comunicación modulan y configuran a la cultura, como las dimensiones múltiples de los medios actuaban sobre las dimensiones múltiples de la cultura.

El libro está compuesto por un trabajo reflexivo y tres estudios de caso: el primero, donde aborda la manera como se ha pensado a la cultura popular en un recorrido que iba de los anticuarios, románticos y eruditos, hasta los neogramscianos, pasa por lo pensado en América Latina, hasta llegar a proponer sus reflexiones personales para estudiar a la hegemonía para enunciar a los Frentes Culturales; los tres restantes son estudios que tienen como objeto una práctica popular: la religión popular al estudiar la práctica de los exvotos y retablitos como una próctica comunicativa; las ferias y la vida urbana como formas de construcción y vivencia de Frentes Culturales. 
escrito en otros libros iniciales sobre las culturas subalternas (González 1990). En la introducción expresaba:

Como resultará claro para el lector, se trata de un elenco de realidades u objetos plurales, aparentemente inconexos salvo por una relación con las clases sociales llamadas "pueblo" y con los modos en que éste se representa la vida y el mundo en que discurre su propia vida en relación con otras representaciones y vidas. Se proponen en fin una serie de reflexiones en torno a un tema común: el estudi de algunos elementos de las culturas contemporáneas en ive 'ico.

O quizás sea mejor decı: estudio de algunos aspectos bastante poco trabajados, de la dinámica y compleja trama de las relaciones que se han tejido y destejido entre los distintos sectores de posiciones sociales y agrupamientos de nuestra sociedad, observadas desde el punto de vista de la construcción y de construcción de "los sentidos o representaciones de la vida y los mundos sociales” (González, 1986:5).

El punto era abordar la hegemonía como una forma de entender la relación social de manera construida histórica y clasistamente, pero la idea era estudiar no lo que distingufa, sino lo que se compartía entre las clases sociales y por ello proponía el concepto, ya señalado, de Frentes Culturales, "que designan una serie de fronteras porosas y simultáneamente arenas o escenarios de lucha por el monopolio legítimo de la legitimación de una cierta manera de gestar y organizar el discurso social común, las formaciones culturales transclasistas o elementalmente humanas" (Idem: 6), y para ello, señalaba, no bastaba indicar que había hegemonía, sino "conocer cómo las ideologías generales se hacen particulares, productos culturales concretos y cómo se establecen relaciones desiguales y desniveladas, pero legitimas entre constructores y usuarios que luchan en torno de algo vital y cotidiano que forma la materia prima del vínculo social" (Idem: 7).

Esto significaba ver a la cultura desde otra óptica diferente a la manera como la sociología, la antropología y la comunicación lo habían hecho de manera tradicional, principalmente con procedimientos normativos, etnocéntricos y esencialistas, y se pasaba a verla de una manera que permitiera acceder y conocer sus variadas inanifestaciones complejas en la vida social, cambiantes y construidas 
históricamente, es decir, verla "como un modo de organizar el movimiento constante de la vida concreta, mundana y cotidianamente" (González, 1987: 8), sin ser un acto reflejo, secundario, ni parcial, sino "una dimensión omni-presente en las relaciones sociales" (Idem., 10), y esto era proponer a la cultura como un dimensión de análisis "de todas las prácticas sociales; es -de acuerdo con una expresión similar de Greimas- la sociedad total, observada, desde la dinámica de la construcción y reelaboración constante, histórica y cotidiana de la significación" (Idem: 11). Además la cultura era planteada como una visión del mundo como un efecto "de las desiguales posiciones dentro de la estructura social, una división práctica, efectiva y operante del mundo" (Idem.). Es decir, la cultura era vista mediante desde una dimensión simbolica de la vida social ${ }^{22}$, presente en todas las prácticas y relaciones de la sociedad, que se manifiesta mediante soportes sociales objetivos y la división social le ha dado maneras como se construyen, codifican e interpretan los sentidos sociales, y por lo mismo, no sólo tiene la posibilidad de significar, sino que sirve para orientar y organizar la acción y composición del mundo social.

Como lo harán otros en América Latina, que comparten sentimientos y contextos similares, la visión de la comunicacion cobraba otra materialidad posible para su estudio: ya no eran los medios de comunicación necesariamente el objeto, sino las prácticas sociales, los objetos, que han sido cargados histórica, social y simbolicamente, y que son las dimensiones y bases para la dimensión comunicacional de la vida social, incluso, para entenđer lo que sucedía

22

La dimensión simbólica de la cultura vista de esta manera implicaba entrar a la manera como se producen los sentidos, las representaciones, las ideologías que orientan y organizan a los individuos cotidianamente, pero no sólo eso, sino que también los individuos participan en la misma producción. construcción y organización de la vida sígnica, y esto, a su vez era reconocer que "construir sentidos implica cuando menos una asimilación, una selección creativa, una reacomodación y una serie de esquemas interpretativo que normalmente operan sobre otras formas pre-existentes o copresentes de nombrar al mundo, de ordenarlo" (González, 1987: 17). La dímensión simbólica de la cultura, al poner la atención a las prácticas y movimientos de los individuos en sociedad, reconocía la acción, negada o no visualizada por las tendencias teóricas predominantes del momento, la acción del sujeto, pero también la diversidad como este participa y elabora representaciones y, por lo mismo de la apropiación y el uso, participación de los productos, objetos y bienes simbólicos, pues una misma realidad social se da de distintas maneras de interpretar/reinterpreturf intervenir en ella. 
con los mismos medios. Era ahí, que un objeto, práctica o sujeto social, adquiría una relevancia no considerada o visualizada anteriormente, y por medio de comprender este universo de relaciones era como lo comunicacional se materializaba.

En 1993 el PC inició una nueva investigación que coordinó Jorge González y que pretendía dar cuenta de la manera como el país se había transformado a lo largo del siglo XX mediante una serie de equipamientos culturales y la manera cómo estos habían generado públicos culturales. Siguiendo los supuestos que se habían conformado desde los inicios de la fundación del PC, la investigación, que en términos simplificados se le llamó "La formación de ofertas culturales y sus públicos" (FOCyP) (González 1994), partía de la necesidad de una serie de carencias de información de y en todo el país sobre la vida cultural, entendida de una manera más amplia y desde la dimensión simbólica de la cultura, para poder ser un instrumento importante para las políticas culturales y generar programas de investigación ${ }^{23}$.

Otro de los investigadores del PC que tuvo una permanencia dentro del centro de investigación, así como una notable influencia dentro de su desarrollo y orientación, y presencia significativa en el campo académico de la comunicación en México, fue Jesús Galindo Cáceres. Con trayectoria paralela a la de Jorge González, pero al mismo tiempo con diferencias significativas, Jesús Galindo estuvo a cargo de la línea de investigación sobre la cultura urbana y los movimientos sociales. La investigación que realizó se denomino "Cultura nacional y la cultura regional", y como en el caso de González, los presupuestos teóricos y metodológicos fueron producto de los trabajos de investigación realizados en los años previos a la fundación del PC, y que se habían aplicado a la ciudad de México, es decir, los años en que realizó sus estudios de maestría (lingüística) y doctorado (antropología) y que lo llevaron a realizar una investigación sobre el movimiento social y la cultura urbana (Galindo 1987). De esos años viene el centro desde donde se desarrolla el pensamiento y el trabajo de indagación de Jesús Galindo que irá desarrollando en el PC.

${ }^{27}$ La primera laguina de información, decía González. "liene que ver con la ausencia de conocimientos sobre la formación y transformación histórica de las ofertas culturales" (Gonzálcz, 1994: 12) y la segunda laguna se refería alos públicos culturales. También. fuce una investigación que se armó a través de grupos de investigación en diferentes partes del país. 
En 1987 publicó su libro Organización social y comunicación, y en él se incluyeron cinco textos que fueron producto de esa época de formación del postrado, y previos a la fundación del PC. Al expresar de lo que trataban esos cinco trabajos, Galindo expresaba:

A grandes rasgos el contenido se ordena alrededor de la problemática de la organización social, la pregunta por la composición del mundo social. En un segundo orden de ideas se plantea la relación entre la composición subjetiva y la objetiva, enfatizando la importancia y la necesidad del análisis de las condiciones subjetivas de la organización social. De esta línea se sigue la perspectiva del trabajo sobre comunicación, entendiendo a esta como la matriz de las relaciones sociales, el medio inmediato de la reproducción o transformación de las condiciones vigentes de composición (Galindo, 1987a: 8).

Galindo parte de dos supuestos que se desarrollaban dentro de las ciencias sociales. El primero se refiere al por qué estudiar a la ciudad, a la cultura urbana. Expresaba que, en esos momentos, había un interés por las culturas populares, por desartollar una aproximación "novedosa" al estudio de lo urbano, y por los estudios de la comunicación, y que las tres vertientes "pueden ser concebidas como maneras distintas y complementarias de aproximación a la organización social, siendo este el asunto central del trabajo teórico práctico en ciencias sociales el día de hoy. Es en esta perspectiva que las tres pueden ser relacionadas con cierta facilidad, sobre todo cuando se piensa en el verdadero problema nuclear de la organización de nuestro sistema de vida occidental, la formación urbana, la ciudad" (Idem: 124).

Por otro lado, está la concepción misma de la organización, la cual la concibe como el objeto de las ciencias sociales, y que la concibe como una manera donde el ser social, el mundo de los hombres adquiere una "una composición, un orden y un sentido, al mismo tiempo que lo que hoy aparece deviene de un marco dinámico anterior y se proyecta a futuros posibles alternativos", por to que la organización de la vida social es "composición múltiple y dinámica, es por ello posible delimitar diferentes niveles de disposición de componentes elementales y complejos, de distribución de acciones y relaciones, de objetos y sujetos, de usos y abusos. La organización social es la trama y urdimbre de las relaciones sociales, es ta multi articulación de las partes al todo" (Idem.). 
Esto hizo que dispusiera de una perspectiva metodologica que se armó alrededor de la manera como las dimensiones espacio-temporal se articulan a la organización social, y, por tanto los distintos niveles (macro, meso y micro) en que se dan y se desarrollan, y ante ello, era necesario el "rescate de todos los niveles de análisis presentes existentes, en la perspectiva de las relaciones y elementos de composición de los niveles; en un ir de lo más general a lo más particular y de lo más particular a lo más general. Esto será posible con mayor intensidad si se parte de una formación social concreta y de una serie de contradicciones y conflictos específicos" (Idem: 125). El punto de partida era, entonces, la vida cotidiana como el punto de enlace de los distintos niveles de la organización social ${ }^{24}$. Y como un elemento central para comprender la organización social, su composición y la disposición de actores, acciones y relaciones, incluía el "eje" comunicación-información.

El conocimiento de la vida urbana no sólo reconocía la importancia del momento, sino algo que será clave en el pensamiento de Galindo: la construcción de "sociedades futuras posibles", es decir, lo que más adelante desarrollará metodológica y conceptualmente como "mundos posibles" a partir de conceptos como sociedad de información y sociedad de comunicación (Galindo 1995). A la mirada antropológica, Galindo agrega la necesidad de la perspectiva sociohistórica para comprender la organización social:

La nueva investigación socio-historica empieza hoy y aquí. Los parámetros del trabajo científico socio-histórico marcan ámbitos

${ }^{24} \mathrm{Al}$ insertar la dimensión espacio-temporal, Galindo reconoce que la cultura urbana no es única y homogenea para todos los casos, sino más bien se caracteriza por su heterogeneidad, "aunque si se puede señalar que existe un haz hegemónico que compone con una apariencia de totalidad única. En una perspectiva de clases, la cultura de las clases dominantes, subalternas, puede definirse como cultura popular, de frente a la cultura del prestigio de las clases dominantes. De esta manera se puede concluir en un concepto de cultura urbana popular con un contenido de clase, con una dinámica propia que depende de la fuerza de la práctica y la conciencia de las clases subalternas, dominadas urbanas" (Galindo, 1987a: 130). La concepción de cultura de la que partía Galindo era la de una perspectiva antropológica, $y$ aunque reconoce los tres niveles analíticos de la organización social (económica, política y cultural-ideológico), lo entendía como componentes de una organización social concreta, pero donde, además, planteaba que cra pertinente incluir las prácticas sociales y la conciencia, es decir, incluir la dimensión objetiva y subjetiva de las tres dimensiones señaladas. 
de su desarrollo, estos ámbitos se ubican en el tiempo y en el espacio: el primer tiempo es ahora, el primer espacio es aquí. Sin ir más lejos en esta proposición, en pocas palabras, el análisis socio-histórico empieza en el entorno inmediato del investigador en el medio donde éste se encuentra ubicado. A partir de ahí los ámbitos crecen y se diversifican; sabiendo el investigador desde dónde mira y cuestiona, podrá relacionar a las partes de la totalidad con mayor precisión. Esta perspectiva apunta al desarrollo de estudios socio-históricos del orden de lo local, de lo regional, sectorial, y desde ahí a lo general. Solo con la conciencia de lo particular y cotidiano se puede ascender a la conciencia de lo general y extraño; el investigador sociohistoriador siguiendo esta ruta estará más cercano que nunca del conocimiento práctico, popular, de la entraña de la vida social misma (Galindo, 1986: 54-55).

Y expresaba que donde tiene respuesta este tipo de preguntas y opticas era en los movimientos sociales y la cultura política, "respuesta que se localiza en el corazón mismo de la pregunta por la historia, los actores sociales y su conciencia de movimiento social, del cambio, de la composición de la organización global y particular. La pregunta por la historia toma forma y presencia cuando se considera en su constitución al actor de la historia, al actor particular y anónimo de la vida social, a la relación entre el actor y su historia. Aquí se plantea esta condición como primaria e irremplazable (Idem.).

Para el abordaje de la investigación "Cultura nacional y cultura regional" Galindo realizo una serie de protocolos de investigación (Galindo 1997), tanto para la parte del trabajo etnografico (Galindo 1990), como de las historias de vida que (Galindo 1997b), junto con el protocolo que realizo para la parte de historias de vida para la investigación FOCyP (Galindo 1997b), se convirtieron en herramientas metodologicas y técnicas de suma importancia para algunos sectores del campo académico de la comunicación, pues cubrían una ausencia sobre metodología cualitativa disponible y accesible en el país. Asimismo, como resultado de la investigación de "Cultura nacional y cultura regional" (Galindo 1994a), produjo un texto metodológico ( Galindo 1994b), que se incorporó al arsenal de metodología cualitativa que comenzaba a producirse en los noventas, pero que también era parte de las plataformas de trabajo de un oficio de investigación, y de una concepción metodológica que iría desarrollando para el estudio 
de la cultura (Galindo 1994c), a partir de su incursión en otras vertientes de conocimiento y más cercanas a las ciencias cognitivas, la sociología reflexiva, el pensamiento cuántico, el paradigma de la complejidad, la ingeniería social y otras tendencias más del pensamiento actual, que lo llevarán a considerar otras maneras muy diferentes de comprender a la comunicación (Galindo 1997c), pero con una continuidad desde lo que había comenzado a desartollar desde los ochentas, donde concebirá a la comunicación no desde su parte instrumental, sino como una forma de configurar lo humano y lo social (Galindo 1995a).

\section{Giros en el pensamiento comunicacional. Para entrar a "un mundo raro".}

En todo trabajo de investigación hay algo que se muestra y algo que se oculta. Lo que se muestra es parte del producto terminado de acuerdo a ciertos cánones académicos y científicos. Lo que se oculta es un proceso más profundo, pero más determinante y significativo, tanto para el trabajo intelectual, la construcción del objeto de estudio y la posición que se asume, conceptual y metodológicamente. Sin embargo, lo que permanece oculto es lo que le da profundidad sobre lo que se trabaja, lo que permite que se alcance niveles de significación colectivamente reconocidos, pertinentes e importantes.

Como dijimos al principio, llegar a ello implica un trabajo reflexivo sobre el mismo sujeto de conocimiento, en un esfuerzo donde la percepción se configura de una manera tal que permite crear tanto los cuadros de representación desde los cuales ha conformado procesos de objetivación de realidades por acceder y conocer, como los procesos como estos se han movido, y al final, se adquiere la perspectiva de lo que se puede estar abriendo en el presente que tiende hacia delante. En lo personar, eso fue lo que sucedió al realizar a profundidad este ejercicio, y en el cual se pudo encontrar mucho de lo que tiende a suceder cuando se pretende realizar un acto de conocimiento mediante un proyecto de investigación. Pero también me permitió entender mejor mi ubicación histórica y social dentro de varios contextos de acción, y, en este caso, en el proceso de conformación de una comunidad de conocimiento, la del campo académico de la comunicación en México. Y en ese punto, pude observar estratos no contemplados del campo en dos niveles: la manera como me incorporé y adquirí varios de sus procedimientos y mecanismos de objetivación, pero también una serie de elementos no contemplados de la manera 
que había actuado en mí, que, a su vez, me permitió reflexionar sobre algunos de los contextos y tendencias actuales del mismo campo académico de la comunicación en México.

Partiendo de esto último, llegaron una serie de reflexiones. $\mathrm{Si}$ bien es necesario considerar que los contextos, dinámicas, sujetos, procedimientos y perspectivas del campo académico de la comunicación son distintos a los que se dieron a mediados de la década de los ochentas del siglo XX, relacionarlos más con una perspectiva histórica, que teórica y epistemológica, permiten crear una distancia sobre gran parte de su forma de actuar. Sólo mencionaré algunos, que en muchos casos deben ser confrontados y profundizados en otro momento.

En primer lugar es importante reconocer que lo que sucede en la actualidad debe ser visto como parte de una construcción histórica, social y cultural donde los sujetos que conformaron la comunidad de conocimiento se siguen moviendo, pero donde sus miradas y trayectorias se han movido, intentando dar cuenta de los mismos cambios en el mundo y de las realidades comunicacionales. Pero también han aparecido otros, que tanto en una búsqueda de continuidad de lo hecho, o buscando nuevas rutas, o bien, ubicados sin tener cabal conciencia de su ubicación tanto de la trayectoria de la que devienen, sina enfocando el momento presente y mirando el futuro. Este contexto hace que la conformación de la comunidad haya ganado mayor complejidad y complicación, que en gran parte es lo que se vive en el mundo, y en los debates de las ciencias sociales, los estudios de la comunicación.

Sin embargo, el contexto contemporáneo puede ser visto si se asume una postura similar a la que realizaron los configuradotes del campo: reflexionar sobre los marcos, condiciones y procedimientos desde donde se genera conocimiento, y el tipo de conocimiento que se está generando. El hecho de que exista un trabajo realizado previamente y los nuevos contextos exigen, a su vez, un esfuerzo mayor de reflexividad, principalmente en lo que se refiere a conformar conocimiento sostenido, sistemático y pertinente que van más allá de cubrir de definir deficiencias teóricas y metodológicas, y donde el referente de la realidad empírica debe ser constantemente visitada, tanto para observarla como para tomarla como una herramienta heurística que ayude a crear teoría fundamentada, y modelos formales de investigación (Rosengren 1995), como fue lo que varios intentaron hacer en su momento y con sus procedimientos disponibles. 
El contexto actual tiene diferencias notables respecto a lo que sucedía en los ochentas, pero es importante considerar que ambos son parte de un proceso. Ahora el contexto es la globalización, que no sólo implica un cambio en la organización y acción del mundo, sino una nueva perspectiva heurística de conocimiento, con lo cual, es importante, para nombrarla y mirarla, recuperar la manera como conceptualmente se fue enunciando, las perspectivas de conceptualización que fue abriendo, y el abanico que hoy día están en juego en su definición y conceptualización. Por ejemplo, a mediados de los ochentas se consideraba a los estudios culturales como un tema y perspectiva importante, y a veces anecdótica o interesante, que ayudaba en parte a entender muchas cosas. Hoy en día la perspectiva cultural es en muchos casos un recurso heurístico y analítico central, aunque algunas tendencias ha sido concebirla como el sustituto o el elemento que ayudará a los estudios de la comunicación a terminar de conformar su propio pensamiento. También, los estudios culturales y los de la comunicación eran un fenómeno sugerente, atractivo, así como incómodo e inquietante donde los pensadores sociales se rehusaban a incluirlo dentro de la teoría social, pero que en la actualidad comienzan a hacerlo y esto propicia algunas alteraciones y modificaciones, pero nuevos retos, en el pensamiento social y comunicacional.

Es por ello que el diálogo con otras disciplinas pasa a otro nivel, y ahí toca encontrar las pautas como lo social se está pensando, así como las nuevas concepciones de la comunicación. Ya no sólo es el paso de la confrontación de las ciencias naturales con las sociales, de los paradigmas sociales del cambio radical o el cambio gradual, de los objetivos y subjetivos, sino de la ciencia tradicional y la ciencia compleja. La tendencia sigue siendo la de las renovaciones y síntesis de lo social y comunicación dentro de la ciencia social clásica, con aquellos enfoques integradores, y atender poco a lo que se abre con lo complejo, que visto desde ahí, muchas cosas que se dijeron, se relativizan y se manifiestan emergencias que apenas son mencionadas, señaladas y abordadas.

Esto mismo se puede comenzar a pensar no solo por sistematizaciones de lo que se ha investigado, sino por las narrativas que han emergido y se han diseminado, pues ello implica tanto la posición de los que han generado conocimiento para observar la realidad social, cultural y comunicacional, como de las mismas realidades que se han conformado. Ganar conciencia de ello sería un 
paso en la epistemología, la metodología y la teoría de la comunicación, algo de lo que hicieron en su momento los configuradotes del campo cuando observaron las tendencias de conocimiento y las llevaron a marcos de discusión y reflexión entre los paradigmas, la epistemología y la metodología que se empleaban, las cuales se mostraron parciales e insuficientes, y su esfuerzo fue un acto creador, tanto para ver realidades más complejas y complejamente, y de configurar procedimientos y miradas para hacerlo. Esto mismo se ha venido realizando en las humanidades y algunas disciplinas de lo social, como es el caso de la historia y de la antropología (Marcus y Fischer 2000).

Sería importante comenzar a observar dos procesos en paralelo: no sólo la manera como los medios de comunicación, y más con los procesos de internacionalización y de una nueva mirada hacia el mundo que se suscitan a partir de acontecimientos internacionales como la escalada del terrorismo internacional y los procesos de reinvención del consumo a través de comercializar los productos y manifestaciones de "otras partes" del mundo, configuran las representaciones y nuevas versiones de la realidad y lo cultural, la continua reinvención del "otro" (Reguillo 2002), sino la manera como desde el campo de la comunicación se han creado "versiones" y procedimientos para acceder, comprender y representar realidades comunicativas. En mi opinión, esto traería un esfuerzo mayor reflexivo que implicaría a los agentes de conocimiento considerar sus contextos y sociales desde donde se observa y objetiva la realidad cultural y comunicacional, en momentos en que las realidades nacionales, internacionales, pero también las regionales se han movido sensiblemente y han colocado la urgencia y necesidad de revisar los modos como hemos pensado las realidades sociales varias, y como estas se están moviendo e implicando dudas sobre las seguridades de las identidades y los territorios donde nos movemos (García Canclini 2002). Pensando en lo expresado por Cliffort Geertz (1989), para el caso de la antropología, que el procedimiento que se introdujo y cambio en mucho su labor de investigación y pensamiento fue la premisa de "estar ahr", debemos considerar que en muchos casos, en la comunicación no basta "estar ahî", sino reconocer que "estamos aquî" y el mundo comunicacional nos lleva a otros lados, a otras realidades, pero también "llega aquif". De hecho, sería la manera de comenzar a crear una visión de lo que acontece al crear los procesos de cómo se expresa que actúa lo global, por las múltiples y diversas referencias 
historicas, culturales, de lo local que configuran ese otro proceso, lo mundial, que así mismo nos permitiría relativizar el supuesto de que todo es en la actualidad debido a la globalización, de que esta se manifiesta de manera homogénea y por la acción de Norteamérica, y comenzar a pensar otros procesos que nos incumben y nos empujan como las relaciones de la modernidad, la postmodernidad, e, incluso, los restos de una pre modernidad actuante y vigente en varios de nuestros entornos nacionales.

Asimismo, está la muestra de lo que se realizo en algunos puntos del proceso de institucionalización del campo académico de la comunicación en el país: la importancia de las trayectorias personales que transitan por el postgrado, la creación de espacios de publicación, de investigación, de dialogo entre la comunidad y con otras comunidades. $\mathrm{Y}$ en ese punto hay una diferencia que es necesario considerar: la importancia de la acción en red. Redes de postgrado, de discusión y dialogo, de publicación, de investígación. Algo que se ha hecho en el pasado muy poco, pero que mostró su pertinencia e importancia por la manera como impacto en la forma de actuar y pensar en el campo de la comunicación, y porque muchos de los que actúan en él son producto de ello. Las redes son un punto pendiente con muchas posibilidades y vetas por abrir. Por ejemplo, en el caso de las propuestas de una integración cultural para América Latina, ante un panorama que se considera grave para la continuidad de las culturas locales latinoamericanas, y que un ejemplo claro es lo que sucede con sus industrias culturales (Bonet 2002), la propuesta viene siendo la de propiciar procesos de gestión cultural, y el reconocimiento de que regiones y localidades deben contar con sus propios procesos de gestión y equipamiento de industrias culturales locales, así como una continua investigación sobre la cultura y las transformaciones culturales, y una visión para todo ello es la de conformar redes de acción cultural (Yúdice 2002).

Hemos de asumir que el mundo ha entrado en un proceso de descentramiento y de aceleración, y que cuando esto sucede, y una de las cosas que emergen son los procesos históricos que la han activado y han conformado su diseño estructural básico y primario. Me parece que esto mismo sucede con la situación del campo académico de la comunicación, y asumirlo, o verlo de esta manera, implica ver los procesos históricos de su conformación, para observar las rutas que se abren cuando las senda parecen agotarse o multiplicarse 
indefinidamente. Las trayectorias históricas seguidas en la constitución del campo académico de la comunicación bien tienen algunas vertientes que es necesario acudir continuamente para conocer no sólo muchas de las maneras como se tiende a objetivar el conocimiento, las maneras como se altera la institucionalización del campo, los nuevos diálogos con realidades emergentes y comunidades académicas, sino para encontrar donde las sendas se detienen y hay que seguir otras, encontrar por donde los nuevos vientos avanzan esperando que alguien observe sus sendas no contempladas. Simplemente es algo que sucedió en su momento, cuando en Guadalajara y Colima, por señalar los espacios académicos abordados, comenzar a poner cimientos en la conformación del campo académico de la comunicación.

\section{Bibliografía.}

ARREDONDO, Pablo (1997). "La génesis de un espacio académico. Notas sobre la construcción del centro de Estudios de la Información y la Comunicación de la Universidad de Guadalajara", en Comunicación y Sociedad. Universidad de Guadalajara, No. 30.

ARREDONDO, Pablo y Sánchez Ruiz, Enrique (1986). Comunicación social, poder y democracia en México. México, Universidad de Guadalajara.

BARNES, Barry (1980). Estudios sobre sociología de la ciencia. Madrid, Alianza Editorial.

BENASSINI, Claudia (2001). "Escuelas de comunicación en México: ¿realidad o imaginario social?", en Diálogos de la comunicación. Felafacas, No. 62.

BENASSINI, Claudia (1994). Entre la rutina y la innovación: los egresados de nuestra carrera. México, Universidad Iberoamericana.

BONET, Lluis (2002). "Industrias culturales, diversidad cultural y desarrollo iberoamericano", en García Canclini, N. (coordinador), Iberoamérica 2002. Diagnóstico y propuestas para el desarrollo cultural. México, Editorial Santillana y Organización de Estados Iberoamericanos.

BOURDIEU, Pierre (1997). “ ¿Qué es hacer hablar a un autor?”, en Capital cultural, escuela y espacio social. México, Editorial Siglo XXI. 
BOURDIEU, Pierre (1997a). "Conversación: el oficio de sociólogo", en Capital cultural, escuela y espacio social. México, Editorial Siglo XXI.

BOURDIEU, Pierre (1995). Respuestas por una antropología reflexiva. México, Editorial Grijalbo.

BURKE, Peter (2000). Historia social del conocimiento. De Gutenberg a Diderot. Barcelona, Editorial Piados.

FUENTES Navarro, Raúl (1999). "La investigación de la comunicación en América Latina: condiciones y perspectivas en el siglo XXI", en Diálogos de la Comunicación. Felafacas, No. 56.

FUENTES Navarro, Raúl (1998). La emergencia de un campo académico: continuidad utópica y estructuración científica de la investigación de la comunicación en México. México, ITESO y Universidad de Guadalajara.

FUENTES Navarro, Raúl (1998a). "Un texto cargado de futuro: apropiaciones y proyecciones de De los medios a las mediaciones en América Latina", en Laverde Toscano, M y Reguillo, $R$. (editoras), Mapas nocturnos. Diálogos con la obra de Jesús Martín Barbero. Colombia, Siglo del Hombre Editores.

FUENTES Navarro (1997). "Consolidación y fragmentación de la investigación de la comunicación en México, 1987-1997", en Comunicación y Sociedad. Universidad de Guadalajara, No. 30. FUENTES Navarro Raúl (1996). La investigación de la comunicación en México. Sistematización documental 1986-1994. Guadalajara, ITESO y Universidad de Guadalajara.

FUENTES Navarro, Raúl (1996a). La emergencia de la investigación académica de la comunicación en la región centro-occidente de México. México, Universidad Iberoamericana León. Cuadernos de Mass Culturas, No. 4.

FUENTES Navarro, Raúl (1994). "La institucionalización académica de las ciencias de la comunicación: campos, disciplinas, profesiones", en Galindo, J. y Luna, C. (coordinadores), Campo académico de la comunicación: hacia una reconstrucción reflexiva. México, ITESO y CNCA.

FUENTES Navarro, Raúl (1992). Un campo cargado de futuro. El estudio de la comunicación en América Latina. México, CONEICC.

FUENTES Navarro Raúl (1991). La comunidad desapercibida. Investigación e investigadores de la comunicación en México. Guadalajara, ITESO y CONEICC. 
FUENTES Navarro Raúl (1988). La investigación de comunicación en México. Sistematización documental 1956-1986. México, Edicom.

FUENTES Navarto, Raúl y Sánchez R., Enrique (1992). "Investigación sobre comunicación en México: los retos de la institucionalizacion", en Orozco G., Guillermo (coordinador), La investigación de la comunicación en México: tendencias y perspectivas para los noventas. México, ULA. Cuadernos de Comunicación y Prácticas Sociales, No. 3.

GALINDO, Jesús (2002). "La comunicación como campo profesional posible. De los oficios por venir". Bajado de: http:// geocities.com/arewara/arewara.htm GALINDO, Jesús (1997). "Programa metodológico de investigación. El caso de la cultura nacional y la cultura regional", en Sabor a ti. Metodología cualitativa en investigación social. México, Universidad Veracruzana.

GALINDO, Jesús (1997a). "Encuentro de subjetividades, objetivjdad descubierta. La entrevista como centro del trabajo etnográfico", en Sabor a ti. Metodología cualitativa en investigación social. México, Universidad Veracruzana.

GALINDO, Jesús (1997b). "Historia de vida. Guía técnica y reflexiva", en Sabor a ti. Metodología cualitativa en investigación social. México, Universidad Veracruzana.

GALINDO, Jesús (1997c). "Fronteras de la comunicación. Preguntas y comentarios". Bajado de: http://geocities.com/arewara/ arewara.htm

GALINDO, Jesús (1995). "De la sociedad de la información hacia la comunidad de comunicación", en Cuadernos del departamento de comunicación del ITESO. ITESO, No. 2.

GALINDO, Jesús (1995a). "La comunicación como mentalidad y como forma de vida. Juego de saberes y sentidos sobre lo humano y lo social", en Galindo, J. y Luna, C. (coordinadores), Campo académico de la comunicación: hacia una reconstrucción reflexiva. México, ITESo y CNCA.

GALINDO, Jesús (1994). "Presentación", en Galindo, J. y Luna, C. (coordinadores), Campo acadéntico de la comunicación: hacia una reconstrucción reflexiva. México, ITESO y CNCA.

GALINDO; Jesús (1994a). Cultura mexicana en los ochenta. Apuntes de metodología y análisis. México, Universidad de Colima. 
GALINDO, Jesús (1994b). Entre la exterioridad y la interioridad. Apuntes para una metodología cualitativa. México, ITESO. Colección Huella, No. 25.

GALINDO, Jesús (1994c). "Desde la cultura y más allá de la cultura. Notas sobre algunas reflexiones metodologicas", en González, J. y Galindo, J. (coordinadores), Metodología y cultura. México, CNCA.

GALINDO, Jesús (1992). "Vía pública, vida pública. De los caminos de la vida y la calle en la organización urbana", en Estudios Sobre las Culturas Contemporáneas. Universidad de Colima, volumen IV, No. 13-14.

GALINDO, Jesús (1990). La mirada en el centro. Vida urbana en movimiento. México, ITESO. Colección Huella, No. 19.

GALINDO, Jesús (1987). Movimiento social y cultura política.

Discurso, conciencia, historia... México, Universidad de Colima.

GALINDO, Jesús (1987a). Organización social y comunicación. México, Premia Editora.

GALINDO, Jesús (1987b). "Encuentro de subjetividades, objetividad descubierta. La entrevista como centro de trabajo etnográfico", en Estudios Sobre las Culturas Contemporáneas. Universidad de Colima, volumen I, No. 3.

GALINDO, Jesús (1986). "Historia y conciencia del México contemporáneo: movimientos sociales y cultura política", en Estudios Sobre las Culturas Contemporáneas. Universidad de Colima, volumen 1. No. 1.

GARCf́A Canclini, Néstor (2002). Latinoamericanos buscando lugar en este siglo. Buenos Aires, Editorial Paidós.

GEERTZ, Cliffort (1989). El antropólogo como autor. Barcelona, Editorial Paidós.

GIMENEZ, Gilberto (2001). "La investigación cultural en México. Una aproximación". Mimeo, bajado de: hitp:// www.crim.unam.mx/cultura

GODOY, Ángela (1994). "Eros, ethos y pathos académicos. Acercamiento impresionista a algunas de las dimensiones de la relación maestro-alumno en las escuelas de comunicación", en Galindo, J. y Luna, C. (coordinadores), Campo académico de la comunicación: hacia una reconstrucción reflexiva. México, ITESO y CNCA.

GOMEZ Vargas, Héctor (2003). Sujeto del mundo, sujeto del conocimiento. $O$ de las perspectivas para construir conocimiento 
en un mundo social complejo", en Texto Abierto. Universidad Iberoamericana León, No. 3-4.

GOMEZ Vargas, Héctor (1990). "Sistematización de las materias de teoría de la comunicación en cuarenta universidades de México", informe inédito de investigación, Maestría en Comunicacion, ITESO.

GONZALEZ, Jorge (1997). "La voluntad de tejer. Análisis cultural, frentes culturales y redes de futuro", en Estudios Sobre las Culturas Contemporáneas. Universidad de Colima, Época II, Volumen III, No. 5.

GONZALEZ, Jorge (1994). "La transformación de las ofertas culturales y sus públicos en México", en Estudios Sobre las Culturas Contemporáneas. Universidad de Colima, volumen VI, No. 18.

GONZALEZ, Jorge (1991). "La telenovela en familia: una mirada en busca de horizonte", en Estudios Sobre las Culturas Contemporáneas. Universidad de Colima, Vol. IV, No. 11.

GONZALEZ, Jorge (1990). Sociología de las culturas subalternas. México, Universidad Autónoma de Baja California.

GONZALEZ, Jorge (1989). "Juego peligroso. Ferias, memorias urbanas y frentes culturales", en Diálogos de la comunicación. FELAFACS, No 23.

GONZALEZ, Jorge (1988). "La cofradía de las emociones

(in)terminables", en Estudios Sobre las Culturas Contemporaneas. Universidad de Colima, Volumen II, No. 4-5.

GONZALEZ, Jorge (1987). "Frentes Culturales. Culturas, mapas, poderes y luchas por las definiciones legítimas de los sentidos sociales de la vida", en Estudios Sobre las Culturas Contemporáneas. Universidad de Colima, Volumen 1, No. 3.

GONZALEZ, Jorge (1986). Cultura (s). México, Universidad de Colima y Universidad Metropolitana Xochimilco.

IBAÑEZ, Jesús (1998). "Los avatares del sujeto", en Ibánez, J. (coordinador), Nuevos avances en la investigación social I. Barcelona, Proyecto a Ediciones.

KUHN, Thomas (1987). La tensión esencial. Estudios selectos sobre la tradición y el cambio en el ambiente de la ciencia. México, Fondo de Cultura Económica y CONACYT.

KUHN, Thomas (1986). La estructura de las revoluciones científcas. México, Fondo de Cultura Económica. $7^{\text {a }}$ reimpresión. 
KUHN, Thomas (1980). "Los paradigmas científicos", en Barnes, B., Estudios sobre sociología de la ciencia. Madrid, Alianza Editorial.

LAKATOS, Imre (1983). La metodología de los programas de investigación científica. Madrid, Editorial Alianza.

LUHMANN, Niklas (1996). La ciencia de la sociedad. México, Editorial Anthropos, Universidad Iberoamericana, ITESO.

MARCUS, George y Fisher, Michael (2000). La antropología como crítica cultural. Un momento experimental en las ciencias humanas. Buenos Aires, Editorial Amorrourtu.

MARQUEZ de Melo, José (1993). "Investigación en comunicación: tendencias de la escuela latinoamericana", en Boletín ALAIC. ALAIC, No. 7-8.

MARTÍN Barbero, Jesús (2000). "Desordenamientos de una comunidad de investigación. Prólogo", en Orozco, Guillermo (coordinador), Lo viejo y lo nuevo. Investigar la comunicación en el siglo XXI. Madrid, Ediciones de la Torre.

MORAGAS, Miquel de (1981). Teorías de la comunicación. Estudios sobre medios en América y Europa. Barcelona, Editorial Gustavo Gili.

OROZCO Gómez, Guillermo (1992). La investigación de la comunicación en México: tendencias y perspectivas para los noventas. México, Universidad Iberoamericana.

OROZCO Gómez, Guillermo (1990). "La formación de profesionales en comunicación: dos perspectivas en competencia", en Las profesiones en México. Ciencias de la Comunicación. México, Universidad Autónoma Metropolitana Xochimilco.

PAOLI, Antonio (1977). Comunicación. México, Edicol.

REGUILLO, Rossana (2002). El otro antropológico. Poder y representación en una contemporaneidad sobresaltada", en Análisi. Universidad Autónoma de Barcelona, No. 29.

ROSENGREN, Kart Eric (1995). "Sustantives theories and formal models. Bourdieu confronted", en European Journal of Communication. Vol 10, No. 1, march.

SANCHEZ R., Enrique (1997). "Algunos retos para la investigación mexicana de comunicación", en Comunicación y Sociedad. Universidad de Guadalajara, No. 30.

SÁNCHEZ Ruiz, Enrique (1992). Tendencias en la investigación sobre televisión en México 1950-1990. México, Universidad de Guadalajara. 
SÁNCHEZ, Ruiz, Enrique (1992a). Medios de difusión y sociedad. Notas críticas y metodologicas. México, Universidad de Guadalajara.

SÁNCHEZ Ruiz, Enrique (1988). La investigación de la comunicación en México. Logros, retos y perspectivas. México, Ediciones de Comunicación.

SÁNCHEZ Ruiz, Enrique (1988a). "Presentación", en Sánchez

Ruiz, Enrique (compliador), La investigación de la comunicación en México. Logros, retos y perspectivas. México, Ediciones de Comunicación.

SÁNCHEZ Ruiz, Enrique (1986). La enseñanza de la investigación de la comunicación en Latinoamérica, en México y en Jalisco. México, Universidad de Guadalajara. Cuadernos de Difusión Científica, No. 5.

VASSALLO DE LOPES, Ma. Immacolata (1999). "La investigación de la comunicación: cuestiones epistemológicas, teóricas y metodológicas", en Diálogos de la Comunicación. Felafacas, No. 56.

VASSALLO DE LOPES, Maria Immacolata y Fuentes Navarro, Raúl (2001). Comunicación campo y objeto de estudio. Perspectivas reflexivas latinoamericanas. México, ITESO, Universidad Autonoma de Aguascalientes, Universidad de Colima, Universidad de Guadalajara.

TOUSSAINT, Florence (1975). Crítica de la información de masas. México, Editorial Trillas.

YUDICE, George (2002). "Las industrias culturales: más allá de la lógica puramente económica, el aporte social", en Pensar Iberoamérica. No. 1, junio-septiembre. Bajado de: http:www.campus-oei.org/pensariberoamerica/ric01 a02.htm ZEMELMAN, Hugo (1992). Los horizontes de la razón. I. Dialéctica y apropiación del presente. Barcelona, Editorial Anthropos y El Colegio de México. 